\title{
The hippocampus reevaluated in unconscious learning and memory: at a tipping point?
}

\section{Deborah E. Hannula* and Anthony J. Greene}

Department of Psychology, University of Wisconsin, Milwaukee, WI, USA

\section{Edited by:}

Joel Voss, Northwestern University Feinberg School of Medicine, USA

Reviewed by:

Joel Voss, Northwestern University Feinberg School of Medicine, USA

Jennifer D. Ryan, University of

Toronto, Canada

Rosanna K. Olsen, Rotman Research

Institute at Baycrest, Canada

\section{*Correspondence:}

Deborah E. Hannula, Department of Psychology, University of Wisconsin, 224 Garland Hall, 2441 Hartford Ave., Milwaukee, WI 53211, USA. e-mail: hannula@uwm.edu
Classic findings from the neuropsychological literature invariably indicated that performances on tests of memory that can be accomplished without conscious awareness were largely spared in amnesia, while those that required conscious retrieval (e.g., via recognition or recall) of information learned in the very same sessions was devastatingly impaired. Based on reports of such dissociations, it was proposed that one of the fundamental distinctions between memory systems is whether or not they support conscious access to remembered content. Only recently have we come to realize that the putative systemic division of labor between conscious and unconscious memory is not so clean. A primary goal of this review is to examine recent evidence that has been advanced against the view that the hippocampus is selectively critical for conscious memory. Along the way, consideration is given to criticisms that have been levied against these findings, potential explanations for differences in the reported results are proposed, and methodological pitfalls in investigations of unconscious memory are discussed. Ultimately, it is concluded that a tipping point has been reached, and that while conscious recollection depends critically on hippocampal integrity, the reach of the hippocampus extends to unconscious aspects of memory performance when relational memory processing and representation are required.

Keywords: hippocampus, amnesia, implicit memory, unconscious memory, relational memory, priming, fMRI, neuroimaging
Memory is a ubiquitous part of our daily experience. It is not just the occasional act of remembering an event or an appointment, or being able to recognize an individual as someone seen in the past, the benefits of previous experience facilitate all aspects of thinking, taking action, and perceiving. Therefore, it is not surprising that the organization of memory, the manner in which it is expressed or used, and its representation in the brain have been of substantial interest to philosophers, scientists, and laypeople alike. The idea that memory can take multiple forms was advocated in the early 1800 s by the philosopher Maine de Biran, who proposed that representative, mechanical, and sensitive memory were differentially associated with conscious awareness, rigid/inflexible behavior, and emotional lability (Maine de Biran, 1804/1929; see also Eichenbaum and Cohen, 2001). Empirical investigations conducted by modern-day cognitive psychologists and cognitive neuroscientists have extended these views, identifying different classes of memory and characterizing their permanence over time, how they might be expressed in thought and action, and whether or not they depend on conscious apprehension of encoded and/or retrieved content. Indeed, it seems that early philosophical ideas were not far from the mark, as much of the driving force behind contemporary research involves identification and differentiation of memory systems and the neural substrates that support them.

Initial evidence for the memory systems view came from nowclassic reports (e.g., Milner, 1962) of spared and impaired memory performances following damage to structures located in the medial aspect of the temporal lobes (MTL; i.e., the hippocampus and adjacent cortical structures in the parahippocampal region). These studies, reviewed briefly below, invariably indicated that performances on tests of memory that proceed relatively automatically (i.e., in the absence of effortful retrieval attempts) and without conscious awareness were largely spared, while those that required amnesic patients to consciously recover (e.g., via recognition or recall) information learned in the very same sessions was devastatingly impaired. Based on reports of such dissociations, it was proposed that one of the fundamental distinctions between memory systems is whether or not they support conscious access to remembered content. This view that memory systems divide on consciousness has now become so ensconced in the field as to be considered essentially a first principle from which new findings can be anchored. Indeed, it has been proposed that one could infer whether or not performance on a particular task was supported by explicit memory processes based on the presence or absence of MTL activity in neuroimaging data (cf. Henson, 2003).

Only recently have we come to realize that the putative systemic division of labor between conscious and unconscious memory is not so clean. Therefore, a primary goal of this review is to examine recent evidence that has been advanced against the view that the hippocampus is selectively critical for conscious memory. As part of this objective, we review evidence for hippocampal involvement in successful memory expression (e.g., in eye movement behavior) when explicit responses are incorrect, hippocampal contributions to learning when participants are unaware of 
the contingencies that support increasingly proficient responding, and hippocampal recruitment during encoding when materials are presented subliminally (i.e., masked from conscious awareness). Along the way, consideration is given to criticisms that have been levied against these findings (provided that they exist), and potential explanations for differences in the reported results are proposed. In addition, some of the methodological and interpretive pitfalls that can undermine claims for or against hippocampal contributions to memory without awareness are considered; these are described in the context of the associative priming literature, which has a relatively long history in the investigation of questions about memory, awareness, and the MTL. It is important to note that findings are reported from several neuropsychological investigations and that many of these were conducted with patients of mixed etiology (e.g., Alzheimer's disease, Korsakoff's syndrome) who were selected based on their documented memory impairment. When findings can be more confidently attributed to the hippocampus (e.g., because recruitment was limited to patients with relatively circumscribed hippocampal lesions) we say so in the text. Ultimately, it is concluded that we have indeed reached a tipping point, and that the role of the hippocampus in memory has more to do with the processing and representational demands of the task at hand than with conscious awareness. The implications of this conclusion for some theoretical perspectives of hippocampal function are briefly considered, and some suggestions are made as to how best to proceed in future work.

\section{HISTORICAL CONTEXT: DISSOCIATION OF CONSCIOUS AND UNCONSCIOUS MEMORY EXPRESSION FOLLOWING AMNESIA}

The nature of the memory impairment following amnesia, and by extension, the role of the hippocampus and adjacent MTL cortical structures in learning and memory has been a source of considerable interest and intense theoretical debate. As described briefly above, one question that has been subject to much disagreement in the literature concerns the proposed selective role of the hippocampus in conscious (i.e., aware or explicit) expressions of memory (cf., Postma et al., 2008; Reder et al., 2009; Henke, 2010). While it is generally agreed that conscious recollection, which involves calling to mind the components of past events and experiences, depends critically on hippocampal integrity, the role of this structure in unconscious (i.e., unaware or implicit) expressions of memory has generally been regarded as far more speculative. Such speculation is well-founded, as several early neuropsychological findings documented dissociations between certain forms of learning, which were intact in amnesia, and the ability to consciously recognize or report information encountered in the context of the associated learning experience. As we shall see, this work inspired theoretical frameworks of hippocampal function that hinged on conscious access to remembered content (e.g., Moscovitch, 1992; Squire, 2004; see also Graf and Schacter, 1985), though not all theoretical perspectives share this view (e.g., Cohen and Eichenbaum, 1993; Henke, 2010).

The critical role played by the hippocampus in conscious retrieval of new memories was evident in the seminal description of the famous amnesic patient H.M., which contains anecdotal descriptions of behavior based on informal interactions and reports of impaired performances on standardized neuropsychological tests of memory (Scoville and Milner, 1957; see also Milner et al., 1968). In each case, the ability of this individual to lay down lasting long-term memory representations amenable to explicit report was severely impaired. For example, when queried a halfhour after taking lunch, it was indicated that H.M. could not recall having gone to lunch, let alone exactly what had been enjoyed or the company he had been in. And in formal testing it was noted that "once he had turned to a new task the nature of the preceding one could no longer be recalled, nor the test recognized if repeated" (Scoville and Milner, 1957; p. 108).

Not long after these initial impairments were documented, what has since been described as an astonishing demonstration of intact learning and long-term retention of novel information was reported by Brenda Milner (Milner, 1962; see also Milner et al., 1998). In this work, H.M. learned, over the course of several trials, to trace within the lines of an object using only the image reflected from a mirror (i.e., the mirror tracing task; see Figure 1A). In keeping with prior observations, this example of preserved motor skill learning was accompanied by an inability to accurately describe the circumstances in which the new skill was acquired and severely impaired recognition of the apparatus that had been used during testing. Such results have since been replicated with the additional striking report that H.M.'s retention of the acquired skill was still evident as many as 359 days after initial exposure to the task (Gabrieli et al., 1993). Importantly, it was also demonstrated that this finding was not limited to mirror tracing as follow-up investigations indicated that H.M. could successfully acquire, and subsequently retain, new motor skills in the context of several other experimental tasks (e.g., rotary pursuit, bimanual tracking, tapping; cf. Corkin, 1968).

The above results provided initial empirical evidence for the multiple memory systems perspective and they also inspired investigators to question whether or not intact long-term learning went beyond the domain of motor skills. That this was indeed the case, was initially reported by Warrington and Weiskrantz (1968; see also, Milner et al., 1968) who showed that amnesic patients, like matched controls, could more readily identify pictures of fragmented words and objects (i.e., identify them in an increasingly degraded form) with repeated exposure to the stimulus set (see Figure 1B). Facilitated identification of degraded pictures was retained from day to day during testing, and savings was documented for one patient even after a 3 month retention interval. This type of learning is an example of repetition priming, which refers to a benefit in performance that accrues with repeated exposure to particular items when memory is tested indirectly - that is, without reference to a memory test or to the fact that some of the items had been seen previously (cf. Schacter, 1987; Richardson-Klavehn and Bjork, 1988). Such effects have also been documented when participants are instructed to complete three letter stems (e.g., POS___ with "the first word that comes to mind." Unbeknownst to the participant, a subset of these stems correspond to words encountered during an earlier study phase (e.g., POSTURE), and priming is evident to the extent that participants complete the stems with studied words more often than would be expected by chance (i.e., without the associated study exposure). With these instructions, which simply 
A

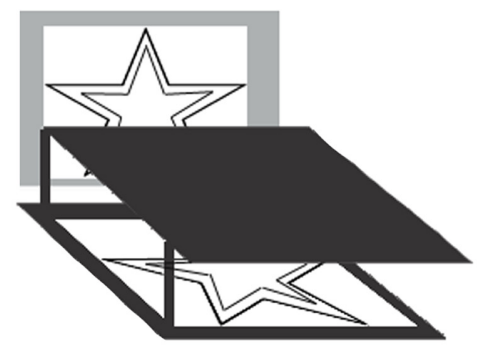

B

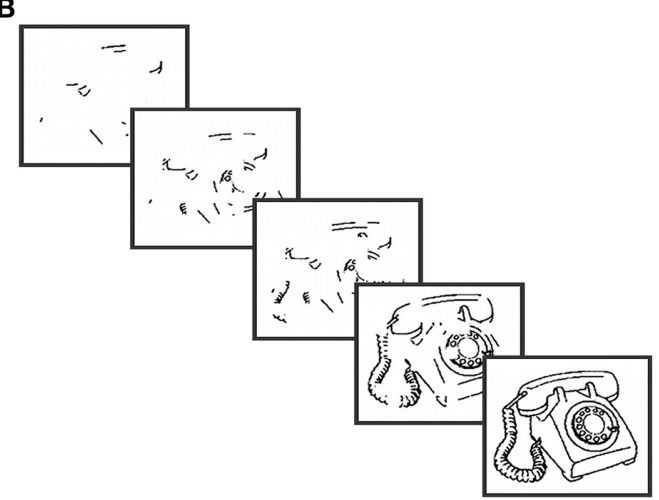

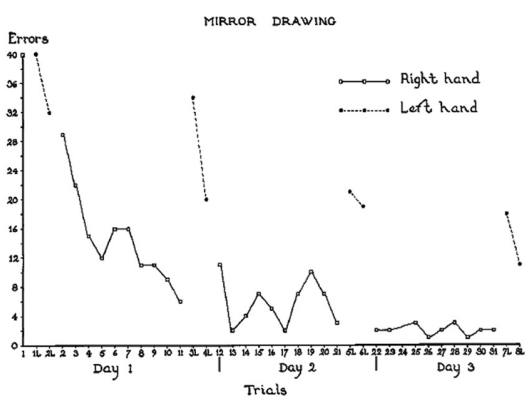

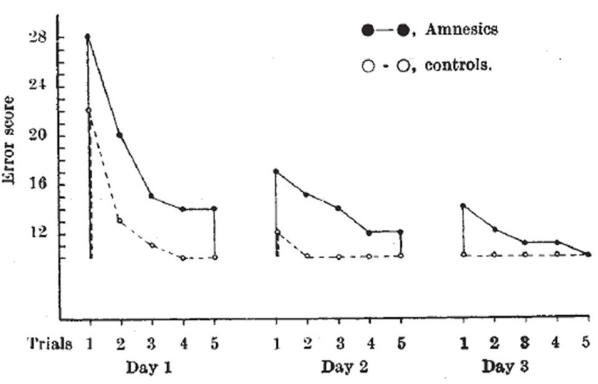

C

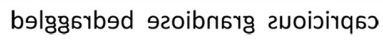

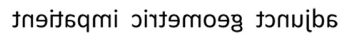

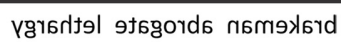

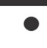

?

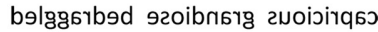

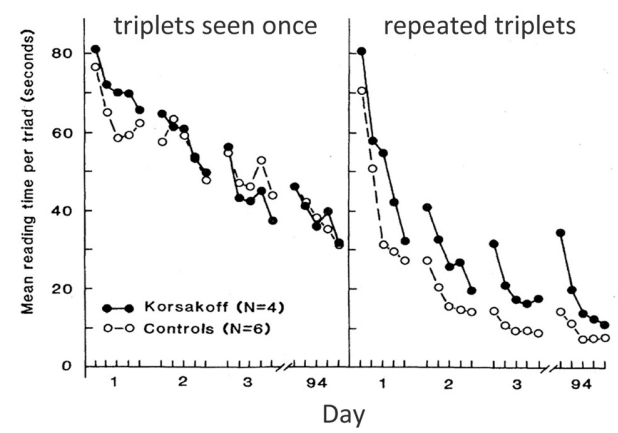

presented repeatedly across several trials and sessions illustrating a reprocessing or priming effect. (C) Left: Illustration of word triplets used in the mirror-reading task. Some of these triplets were seen just once, others were repeated several times during testing. Participants were to read each triplet as quickly as possible when it was presented. Right: Performance of amnesics and controls on the mirror reading task reported by Cohen and Squire (1980). Mean reading times of patients and controls decreased consistently across several days of testing providing evidence for intact perceptual skill learning in amnesia. Patients did not benefit as much as controls from repeated presentations of the same triplets. [Figure 1A, right, reprinted with permission from Elsevier; Figure 1B, right, reprinted by permission from Macmillan Publishers Ltd;

http://www.nature.com/; Figure 1C, right, reprinted with permission from AAAS; http://www.aaas.org/]. orient participants to the stem-completion requirement, the task is "treated more as a 'guessing game' than a formal test of memory" (Warrington and Weiskrantz, 1968; p. 974), and amnesic patients perform much like controls. In contrast, when instructions reference prior experience, as in cued recall or recognition, learning effects observed in amnesia are much reduced (e.g., Warrington and Weiskrantz, 1968; Squire et al., 1978).

Following on the heels of these reports, intact performances on cognitive (e.g., Tower of Hanoi; see Cohen, 1984) and perceptual skill learning tasks were also observed (Cohen and Squire, 1980). In one of these experiments (Cohen and Squire, 1980), amnesic patients acquired a pattern analyzing skill (i.e. reading mirror reversed text) as quickly as a control group, but failed to show the normal amount of additional facilitation to a subset of word triplets that were presented 20 times over the course of the experiment (see Figure 1C). The small amount of repetition-based facilitation that was evident in the performances of amnesic patients was subsequently considered akin to effects of perceptual 
priming, and controls were said to have shown greater benefit of repetition because unlike patients, they had explicit knowledge of the repeated items and could likely retrieve the remaining two words after having read the first (Cohen, 1984). Indeed, when participants were asked about the occurrence of repetitions, patients indicated that there were none, whereas controls reported them spontaneously. A more objective assessment revealed that explicit recognition was severely impaired among amnesic patients, even for the subset of words seen 20 times previously. Such results provide strong evidence for dissociation of skilled performance on the one hand and conscious recollection of the events surrounding learning on the other.

\section{MODELS OF HIPPOCAMPAL FUNCTION: A RANGE OF PERSPECTIVES ON CONSCIOUSNESS}

It was based on reports like those described briefly above that the initial distinction between declarative ("knowing that") and procedural ("knowing how") memory systems was drawn (Cohen and Squire, 1980). According to this perspective, the hippocampal system (i.e., the hippocampus along with the entorhinal, perirhinal, and parahippocampal cortices) is critically involved in the representation of a particular type of memory, declarative memory, which is selectively compromised in amnesia. Because memory for the procedures or operations that support normal acquisition of skilled performance was largely preserved, it was proposed that a different brain system must support procedural memory. Borrowing from the nomenclature of Bruner (1969), knowledge garnered by the procedural memory system was said to be without record (inaccessible to verbal reports; absent any explicit knowledge of events surrounding learning), and to reflect the tuning and modification of dedicated cortical and subcortical processors that are engaged during the performance of a particular task. Declarative memory was said to be with record (consciously accessible; amenable to verbal report) and to reflect the combined outcomes of having engaged said processors (Cohen, 1984; Squire and Cohen, 1984). The resulting declarative memory database "provided the basis for access to facts acquired during the course of experience and for conscious recollection of the learning experiences themselves" (Cohen, 1984; p. 97). Most important for the purpose of this review, contemporary versions of this theory continue to share in common with a handful of other models (e.g., Moscovitch, 1992) the proposed dichotomy between aware and unaware expressions of memory, and their dependence or not on structures in the hippocampal system (cf. Squire, 2004; Squire et al., 2004).

The proposed link between conscious awareness and hippocampal system function has perhaps been articulated most strongly in the component process model developed by Moscovitch and colleagues (e.g., Moscovitch and Umilta, 1991; Moscovitch, 1992). According to the model only information that has been consciously apprehended is encoded by the hippocampal system, which then integrates the elements of that event, and the conscious experience of it, into a memory trace. An index of this memory trace is laid down in the hippocampus and can subsequently be used to recover the components of previously experienced events when associatively bound cues are available. The components themselves (e.g., faces, objects, words) are represented in domain-specific posterior neocortical (and other) modules that process and store perceptual and conceptual records of stimulus input. As an aside, processing mediated by these domain-specific modules is said to be sufficient for item-specific (e.g., repetition priming) or skill-based (e.g., mirror tracing) implicit memory expression, a view that is generally consistent with what has been proposed in the context of other models described here (e.g., Cohen and Eichenbaum, 1993; Squire, 2004; Henke, 2010). Returning to the hippocampal system, explicit recovery of memories for past events and experiences (i.e., episodic memory) depends on an effective cue, which triggers the hippocampal index and elicits automatic and obligatory recovery of associated elements as well as the conscious experience of the original event. The retrieval process is said to be automatic because events are often remembered without intention-they "pop into mind much as preattentive perceptual stimuli pop out of their background" (Moscovitch, 1992; p. 260) ${ }^{1}$. Important for our purposes, a distinguishing feature of this model as it was originally articulated is that consciousness is built into newly established hippocampus-dependent memory representations, and is automatically recovered during retrieval.

Notably, a recent extension of the component process model seems to exercise a bit more flexibility with respect to consciousness of hippocampus-supported memory expression (Moscovitch, 2008; see also Sheldon and Moscovitch, 2010). Specifically, it is now suggested that conscious recollection involves (at least) two separate, but interacting stages of processing. During stage one, studied content is retrieved automatically and obligatorily without concomitant awareness in a process mediated by the hippocampal system. Successful associative retrieval at this stage of processing may be revealed when indirect testing methods are used (e.g., speeded lexical decision, eye tracking). During the second, slower stage of processing, retrieved content becomes consciously accessible and can influence explicit responses (e.g., on recall or recognition tests) in a process said to be mediated by interaction of the hippocampal system with prefrontal and perhaps parietal lobe structures. Based on this proposal, one might infer that when the second stage of processing is disrupted or deficient indirect testing measures will reveal evidence of hippocampus-dependent memory in the absence of associated awareness (cf. Hannula and Ranganath, 2009).

While there is an undeniable link between the MTL memory system and conscious memory expression, there is sharply declining acceptance of the hypothesis that conscious memory is the linchpin function of the hippocampus. For example, in a direct extension of the declarative memory theory, Cohen and Eichenbaum (1993; see also Eichenbaum et al., 1994) proposed that structures in the parahippocampal region (i.e., the perirhinal, parahippocampal, and entorhinal cortices) support

\footnotetext{
${ }^{1}$ While hippocampus-dependent encoding/retrieval processes are characterized as automatic in the model, this does not preclude the possibility that such processes can be influenced by instruction, task demands, or strategy. Indeed, recent work indicates that memory is improved by encoding strategies that depend critically on hippocampal integrity (e.g., Voss et al., 2011). Additional detail about the characterization of hippocampal function as automatic and/or obligatory can be found in Moscovitch (1992).
} 
memory for individual items and that the hippocampus itself is critically involved in binding together arbitrary (i.e., nonderivable) relationships among items encountered in the context of some scene or event. A key property of the resulting relational memory representations is compositionality-individual items retain their representation in memory independent of, and in addition to, the larger relational structure in which they are bound. Compositionality permits flexible memory expression which means that relational memory retrieval is not rigidly tied to the particulars of the original learning experience or the environment associated with memory acquisition; hippocampusdependent relational memories can be expressed in variety of contexts and in response to any number of relationally bound cues. In contrast, rigidly bound (or fused) associations, those that lack flexibility and compositionality, are said to be the province of structures in the parahippocampal region (e.g., Eichenbaum and Bunsey, 1995; Pascalis et al., 2009). On this view, "the hippocampal system plays only an indirect role in consciousness-it organizes the database, so to speak, on which other brain systems may operate and, in so doing, determines the structure and range of conscious recollections" (Cohen et al., 1997; p. 148; see also Ryan and Cohen, 2003; Moses and Ryan, 2006). The modified version of the component process model (Moscovitch, 2008), which postulates a two-stage retrieval process, appears to share at least certain aspects of this view - namely, that processing mediated by the hippocampal system during retrieval provides the raw materials (i.e., reinstates previously bound elements) that may then be communicated with other brain regions to support conscious memory performance. Importantly though, neither the component process model nor the declarative memory theory ( $\mathrm{cf}$. Squire et al., 2004) distinguish between types of representation mediated by the hippocampus and adjacent MTL cortical structures as is done in the relational memory theory.

One final model to be considered here, which diverges most noticeably from views of hippocampal function in which conscious awareness plays a prominent role, was proposed recently by Henke (2010). According to the model, memory systems are best distinguished not on the basis of conscious apprehension, but rather by the type of processing they support. In this case, conscious awareness of encoded and retrieved content does not influence which processing mode is engaged, and therefore does not figure into the model. Instead, processing modes and the memory systems on which they depend are differentiated based on the speed of memory acquisition (i.e., rapid, single trial learning vs. slow, incremental learning), the number of elements to be encoded (i.e., single items vs. associations), and the flexibility of the resulting memory representations. Rapidly encoded novel associations that lend themselves to flexible memory expression are said to depend upon interactions between the hippocampus and specialized neocortical processing sites. When encoding is temporally extended (i.e., involves more than one study exposure) the hippocampus might augment performance early in learning, but would not be required for successful memory acquisition. Instead, temporally extended learning is said to depend critically on interaction of neocortical structures with the basal ganglia, the cerebellum, or the parahippocampal gyrus depending upon task demands. The end result of having engaged in repeated processing of the same information is an inflexible, rigidly bound associative memory representation. A final processing mode, which involves rapid encoding of single (or unitized) items, is said to depend critically on the parahippocampal gyrus. While this model clearly shares several features in common with the relational memory theory, no strong claims have been made in the context of the relational memory theory as to whether or not hippocampusmediated encoding can proceed subliminally. More generally, the proposal that the hippocampus is absolutely unnecessary for learning when repeated study exposures are provided represents a departure from the relational memory theory, which emphasizes representational characteristics of hippocampus-dependent memory above all else.

As can be seen, the models of hippocampal (and hippocampal system) function described here, which represent a subset of those proposed in the literature, provide a range of perspectives on the relationship between the hippocampus and conscious apprehension of retrieved and/or encoded content (for a summary see Table 1). In the paragraphs that follow, evidence for and against the proposed role of the hippocampus in memory without awareness is evaluated. For ease of comparison to the models described above, these studies are considered separately as a function of whether they were designed to investigate hippocampal involvement in implicit memory retrieval, implicit learning that develops over the course of several experimental trials, or implicit (and in the examples provided, subliminal) encoding. First, however, findings from the associative priming literature are used to illustrate some of the investigative pitfalls that can complicate interpretation of results reported in studies of unconscious learning and memory. As part of this objective, we highlight two important issues: (1) the potential for explicit memory contamination on indirect tests of memory, and (2) the need to characterize the nature of the underlying memory representations that support performance on these tests. Following discussion of these issues, we shall see that the associative priming literature provides some initial evidence in favor of the view that the hippocampus does indeed play a critical role in unconscious memory expression even when strict criteria are in place to minimize explicit contributions to performance.

\section{ASSOCIATIVE PRIMING: IDENTIFYING INVESTIGATIVE PITFALLS IN STUDIES OF "UNCONSCIOUS" MEMORY}

The initial collection of investigations designed to identify spared and impaired memory performances in amnesia, described briefly in the opening section, provides strong support for theoretical positions that postulate a divide in memory systems based on whether or not conscious awareness accompanies demonstrations of successful retrieval. The priming literature, for example, demonstrated normal or near normal retrieval of studied content, but only when indirect testing methods were used (cf. Schacter, 1987). A limitation of these studies was the selective assessment of memory for individual items. Whether or not the same pattern of performance would be observed for tests of memory that required participants to form new associations among items that did not have pre-existing relationships had yet to be examined. In the event that they could be documented, demonstrations of intact priming for novel associations in amnesia would further 
Table 1 | Summary of hippocampal models and associated perspectives on requirements for consciousness of encoding and retrieval.

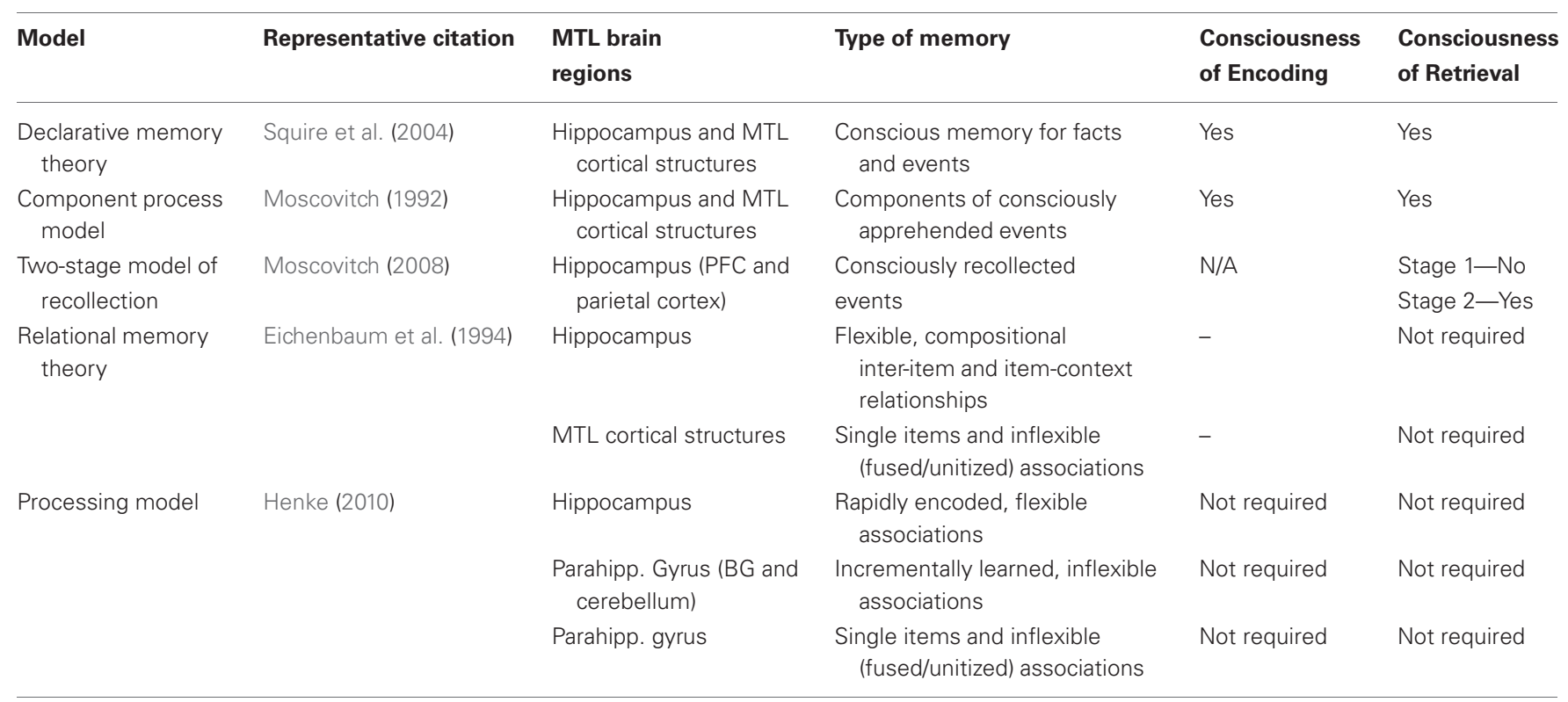

MTL cortical structures include the perirhinal, parahippocampal, and entorhinal cortex; BG, basal ganglia; PFC, prefrontal cortex; -, not explicitly described in the model. Note that the 2-stage model of recollection is an extension (and subset) of the component process model.

substantiate claims that the hippocampus was not required for, and does not support, unaware expressions of memory.

In the mid-1980s, two independent research groups provided initial reports of intact associative priming in memory impaired individuals (Graf and Schacter, 1985; Moscovitch et al., 1986). In both studies, implicit memory for unrelated word pairs was spared despite gross impairment of explicit memory for the same materials. This outcome seemed not to depend upon the exact testing methods that had been used, as different paradigmatic approaches were adopted by the two groups. In one case (Graf and Schacter, 1985), the dependent measure was successful cued stem-completion. Following a study phase in which participants generated sentences that incorporated both words from unrelated cue-target pairs (e.g., KINDLYSTICK $\rightarrow$ the kindly woman picked up the stick) an indirect stem-completion test was administered. Results showed that both patients and controls were more likely to complete stems with studied targets when cue-target pairs were intact (e.g., KINDLYSTI___ than when they were not (e.g., IRRATIONAL-STI__). In the remaining case (Moscovitch et al., 1986), the dependent measure was reading speed. During a learning phase participants read several unrelated word pairs (e.g., MERCHANTTRIBUTE, DAMPNESS-SILENCE, JOURNEY-TREMBLE) and were instructed to study them. Shortly thereafter, with speeded reading instructions, patients and controls read lists of intact pairs (e.g., MERCHANT-TRIBUTE) more quickly than lists of re-arranged pairs (e.g., DAMPNESS-TREMBLE). Because the individual words had been studied in both experimental conditions, the resulting facilitation was attributed to implicit memory for previously presented associations. Based on these outcomes, it was concluded that the hippocampus and related limbic structures were not critical for the initial acquisition and subsequent retention of novel associations; rather, their role was to "make newly acquired information available to consciousness" (Moscovitch et al., 1986; p. 345).

At face value these results seem difficult to reconcile with the relational memory theory (Cohen and Eichenbaum, 1993) and related models (Henke, 2010), which propose a critical role for the hippocampus in relational memory processing and representation with or without awareness. But, as described in the sections that follow, the results reported in these early experiments were not always successfully replicated. In the wake of these failed replications, researchers became increasingly convinced that explicit memory processes were contributing to cued stemcompletion performance (e.g., Shimamura and Squire, 1989; Bowers and Schacter, 1990; Reingold and Goshen-Gottstein, 1996; McKone and Slee, 1997; Gooding et al., 1999), and that speeded reading was often mediated by inflexible perceptual or production-based memory representations (e.g., Poldrack and Cohen, 1997). According to the relational memory theory (Cohen and Eichenbaum, 1993; Eichenbaum et al., 1994; Eichenbaum and Bunsey, 1995; Cohen et al., 1997) and the processing model proposed by Henke (2010), this type of representation should not depend critically on hippocampal integrity. Because issues of awareness and representation require careful consideration in any claim for or against a role for the hippocampus in unconscious memory, relevant findings from the associative priming literature are considered in the sections that follow.

\section{CONFOUNDING EFFECTS OF EXPLICIT MEMORY CONTAMINATION}

One of the greatest challenges posed by investigations of implicit memory is the development of a paradigm that can be used to index past experience absent any confounding effects of conscious awareness. Without rigorous tests, explicit 
contributions to performance can go undetected and the use of incidental instruction alone does not eliminate this confound (e.g., Bowers and Schacter, 1990). Following the initial report of intact cued stem-completion in amnesia (Graf and Schacter, 1985), reanalysis of the original data, combined with a new follow-up investigation, revealed that only those patients characterized as having "mild" memory deficits showed intact associative priming (Schacter and Graf, 1986). Indeed, with just one exception (Cermak et al., 1988a) work conducted with amnesic patients by other labs indicated that any benefit of context reinstatement in the cued stem-completion paradigm was negligible (Cermak et al., 1988; Mayes and Gooding, 1989; Shimamura and Squire, 1989). Insight into what might be driving this idiosyncratic pattern of results was provided by experiments conducted with neurologically intact college-age participants who completed post-test awareness questionnaires. Based on their responses, it was found that only those participants classified as "test-aware" showed associative priming on the stem-completion test (Bowers and Schacter, 1990; McKone and Slee, 1997; Gooding et al., 1999). Even more problematic, a subset of participants confided that they had deliberately completed the stems with a word that had not been studied (McKone and Slee, 1997; Gooding et al., 1999). Based on this evidence, there is general agreement that associative priming elicited by cued stem-completion is influenced by explicit memory contamination (cf. Schacter et al., 2004), and under these circumstances impaired performance among amnesic patients is not surprising.

This line of work is instructive because it illustrates how explicit retrieval processes can contaminate performance on indirect tests of memory. However, it is important to note that the reported outcomes do not completely preclude the possibility that associative priming was mediated by unconscious processes on a subset of the trials, or the possibility that performance on a given trial might reflect both unconscious and conscious influences. Consistent with the first possibility, Bowers and Schacter (1990) suggested that test-awareness may have developed consequent to several successful completions when intact cue-target pairs were presented. This proposal was challenged by McKone and Slee (1997) who had "aware" participants identify the pair from the stem-completion task that they felt had triggered their awareness. Based on these subjective reports it was determined that awareness developed early in testing, and summary statistics limited to trials preceding awareness provided no evidence for associative priming. Importantly, caution was advised in the interpretation of this result because it was based on so few trials. Of additional concern, because the awareness questionnaire was administered after completion of the indirect test, participants may have misestimated when awareness emerged or may not have even had access to this information (Tversky and Kahneman, 1974). Under these circumstances, they may have simply selected the first pair from the list that they recognized now, after having been informed of the link between study and test.

Even if we assume that associative priming in the cued stemcompletion paradigm was never strictly implicit, performance on individual trials may have been influenced by both unconscious and conscious memory processes (cf. Gooding et al., 1999). This possibility is consistent with the recently proposed modifications of the component process model described above, in which it is indicated that conscious recollection is a two-stage process (Moscovitch, 2008; Sheldon and Moscovitch, 2010). Specifically, because cued stem-completion tests are not speeded, and therefore provide ample time for the second stage of processing to proceed, awareness of successful completions may emerge even if the initial retrieval process was not consciously mediated. To the extent that both processes are implicated in cued stem-completion performance, the relative absence of associative priming in amnesia may indeed reflect genuine implicit associative memory impairment. This possibility cannot be dismissed on the basis of post-test awareness questionnaires, and would likely benefit from additional investigation with methods that can more precisely estimate the time-course of memory processes that emerge over the course of individual experimental trials (e.g., event-related potentials, magnetoencephalography).

\section{CHARACTERIZING MEMORY REPRESENTATIONS THAT SUPPORT PERFORMANCE}

Consistent with findings that conscious memory processes are relatively slow to develop (e.g., Yonelinas and Jacoby, 1994), alternative methods that emphasized rapid responding were also used in associative priming investigations to more effectively minimize explicit memory contamination. As indicated earlier, intact associative priming in memory impaired individuals was initially documented not only with stem-completion, but also in a study that used speeded reading as the dependent measure (Moscovitch et al., 1986). The first attempted replication of this result was unsuccessful (Musen and Squire, 1993), but in this case, associative priming was absent from the performances of patients and controls alike, which raised concerns that there may have been insufficient power to detect a statistically significant difference in reading time across lists of intact and recombined word pairs (Light et al., 1996; Poldrack and Cohen, 1997). In line with this possibility, affirmative evidence for associative priming in speeded reading was reported in a subsequent experiment conducted with college-age participants (Poldrack and Cohen, 1997). Having replicated the result, the investigators went on to examine the nature of the newly acquired memory representations. Results showed that reading-based response time facilitation for intact pairs at test was much reduced when the first and second word in a pair had swapped positions (e.g., study: WINDOW-REASON; speeded reading: REASON-WINDOW) and was completely absent when a word was interposed between the paired items (e.g., study: WINDOW-REASON; speeded reading WINDOW and REASON). Similar results were reported in a speeded lexical decision task when paired words were presented sequentially, rather than simultaneously, disrupting previously established perceptual gestalt (Goshen-Gottstein and Moscovitch, 1995). Such findings imply that new learning was due to the acquisition of an inflexible or rigidly bound memory representation that could only support associative priming when word pairs were presented exactly as they had been seen or spoken during encoding.

Under these circumstances performance may reflect the operation of the same specialized neocortical processors that have been implicated in single item priming and procedural learning 
(Henson, 2003), or the operation of binding mechanisms in the parahippocampal region that can support memory for unitized word pairs (e.g., Quamme et al., 2007; Haskins et al., 2008; see also Erikson and Desimone, 1999). Because specialized neocortical processors are not typically compromised in amnesia, and because there may be some sparing in the parahippocampal region, amnesic patients might be expected to show normal levels of associative priming when basic perceptual properties encountered during study are reinstated on the indirect test. Results largely confirm these expectations (Gabrieli et al., 1997; GoshenGottstein et al., 2000; Verfaellie et al., 2006). However, when this constraint was not met-for example, when paired words were presented sequentially rather than simultaneously-amnesic performance has typically been impaired (Paller and Mayes, 1994; Savage et al., 2002; Carlesimo et al., 2005); this is a finding to which we will return.

Notably, at least one set of results is not easily accommodated by the above dichotomy. Despite the use of methods that retained the perceptual gestalt of intact pairs when memory was tested indirectly, Yang et al. (2003) reported that associative priming was impaired, and indeed absent, among amnesic patients who completed their experiment. This finding is even more remarkable because participant recruitment was limited to patients who had relatively selective MTL lesions, and several procedural details were in place to preclude explicit contamination. Critically, a follow-up fMRI investigation conducted with neurologically intact participants localized the associative priming effect to the parahippocampal cortex (Yang et al., 2008). To the extent that performance on this task was supported by a fused representation of studied associations, such results would be predicted by the relational memory theory and by Henke's processing model; in contrast, the reported outcome presents a challenge for the declarative memory theory, which proposes that memory processes mediated by MTL structures are necessarily available for conscious report (e.g., Squire, 2004).

So as not to leave any loose ends, and because one of these investigations is especially relevant to questions about a potential role for the hippocampus in implicit memory, we now return to findings of associative priming impairment with sequential testing procedures noted briefly above (Paller and Mayes, 1994; Savage et al., 2002; Carlesimo et al., 2005). As you may recall, effects of associative priming were abolished when such procedures were used with college-age participants, an effect that was attributed to disruption of perceptual gestalt (Goshen-Gottstein and Moscovitch, 1995). So why then was associative priming successfully documented among controls recruited to participate in the neuropsychological investigations? It seems likely that combined use of multiple encoding exposures (i.e., between two and six across experiments) and requirements to perform at least two different elaborative encoding tasks during the study phase may have been contributing factors. Such manipulations may have minimized the acquisition of fused perceptual representations, supporting instead, the acquisition, and subsequent use of higher-order relational memory representations. These representations, which by some accounts (e.g., the relational memory theory) are said to depend critically on hippocampal integrity, may then have been better suited to support successful associative priming among controls when sequential testing procedures were used.

One of these investigations (Carlesimo et al., 2005) is particularly notable because associative priming was absent only from the performances of amnesic patients who had selective hippocampal damage; those with amnesia consequent to thalamic or basal forebrain damage, in whom hippocampal volumes were within normal limits, had associative priming scores that were fully intact, and even numerically larger than the same effect in control data. That explicit contamination was unlikely to have influenced performance is suggested by savvy methodological choices-intact pairs were rarely encountered on the indirect test (i.e., the number of trials was large, but few of these trials were intact pairs) and the first item from each pair was presented very quickly (i.e., $300 \mathrm{~ms}$ ) and immediately replaced by the second item, which remained in view until participants indicated whether it was a word or a nonword. This approach provides little incentive to engage in effortful retrieval attempts and little time for strategic processing of the first word from a given pair. Consequently, this result provides strong evidence for hippocampus-mediated associative priming, even in the absence of awareness.

\section{CONVERGING EVIDENCE FOR HIPPOCAMPUS-SUPPORTED UNCONSCIOUS MEMORY}

The number of investigations that point to hippocampal involvement in learning and memory without awareness has increased substantially in recent years, making a strict division of labor across memory systems based solely on subjective memory outcome less tenable (cf., Reder et al., 2009; Henke, 2010; Dew and Cabeza, 2011). While some of the reported findings have been subject to debate, the evidence does indeed suggest that we have reached a tipping point. In what follows, recent evidence for (and in some cases against) hippocampal involvement in unaware expressions of memory is presented. As indicated earlier, these studies are considered separately based on whether they were designed to investigate hippocampal involvement in implicit memory retrieval, implicit learning, or implicit encoding. As will be seen, some of the models described earlier can accommodate the reported findings more easily than others.

\section{EVIDENCE FOR HIPPOCAMPUS-SUPPORTED RETRIEVAL WITHOUT AWARENESS}

We have already seen at least one example from the associative priming literature that provides compelling support for the proposal that hippocampal function extends beyond conscious memory expression (i.e., Carlesimo et al., 2005). The evidence is convincing not only because the task was carefully designed to minimize explicit contributions to performance, but also because impairments were evident only among amnesic patients with selective hippocampal damage. These results are complemented by converging reports of impaired associative priming from a handful of other investigations that also used sequential testing procedures (Paller and Mayes, 1994; Savage et al., 2002) and by reports of impaired associative priming when information from different modalities (e.g., voice-word associative priming) must be bound to support performance (Schacter et al., 1995; see also Curran and Schacter, 1997). However, because patients 
in the latter studies were of mixed etiology, impaired performances cannot be attributed unambiguously to the hippocampus. A converging methods approach could help disambiguate these findings, but unfortunately most neuroimaging investigations have focused on identification and characterization of the neural substrates of single item priming (Henson, 2003). Among the associative priming studies utilizing neuroimaging methods (Mayes et al., 1998; Badgaiyan et al., 2003) concerns have sometimes been raised that performance may have been subject to explicit memory contamination, which then precludes conclusions about a role for the hippocampus in unconscious memory.

Another approach used to examine hippocampus-dependent implicit memory expression takes advantage of the fact that eye movement behavior is influenced by prior exposure to visual materials (see Hannula et al., 2010 for review). In several experiments, it has been demonstrated that eye movements distinguish studied from novel items (e.g., Althoff and Cohen, 1999), and that patterns of viewing can provide evidence of memory for inter-item and item-context relationships (e.g., Ryan et al., 2000; Hannula et al., 2007). These eye-movement-based memory effects are expressed rapidly and obligatorily in patterns of viewing (e.g., Ryan et al., 2007), occur well in advance of explicit recognition responses (e.g., Hannula et al., 2007, 2012), and have even been documented in the absence of conscious access to retrieved content (e.g., Ryan et al., 2000).

When combined with neuropsychological or neuroimaging methods, eye movement investigations provide insight into hippocampal function. For instance, it has been demonstrated that like neurologically intact controls, amnesic patients with hippocampal damage make fewer fixations and sample fewer distinct regions of previously studied as compared to novel items (e.g., faces, buildings, scenes; Althoff and Cohen, 1999; Ryan et al., 2000) and they do so despite poor recognition of the same materials (Althoff et al., 1993; Althoff, 1998). This intact eye-movement-based reprocessing, or repetition, effect resembles findings of intact repetition priming described earlier. In contrast, amnesic patients fail to benefit from prior exposure when relational memory is tested. In one of these investigations (Ryan et al., 2000), participants were presented with pictures during a test phase while their eye movements were recorded. Some of these pictures were seen previously and remained unchanged, others had also been seen previously, but were now systematically manipulated such that relationships among scene elements had changed (e.g., soap to the left of the sink was now to the right of the sink). Under these circumstances, neurologically intact individuals looked disproportionately at the part(s) of the scene that had been manipulated, and did so even when they failed to report the difference explicitly. The same eye-movement-based relational memory effect was completely absent from the viewing behavior of amnesic patients, including those with damage limited to the hippocampus (Ryan and Cohen, 2004). Such results suggest that the hippocampus is critical for relational memory, irrespective of whether or not said memory is accessible to awareness, and are predicted by the relational memory theory (Cohen and Eichenbaum, 1993) and by Henke's processing model (2010).
Recently, it was reported that disproportionate viewing of scene changes was only evident when participants were aware that the change had been made (Smith et al., 2006). Based on this null result, it was said that patients in the study conducted by Ryan et al. (2000) failed to show the viewing effect because it depends on awareness. However, changes in viewing behavior absent awareness have been successfully documented in several other experiments (Hayhoe et al., 1997; Hollingworth et al., 2001, 2008; Hollingworth and Henderson, 2002; Henderson and Hollingworth, 2003; Beck et al., 2007). As such, the result reported by Ryan et al. (2000) can arguably be said to provide a second strong demonstration of hippocampal involvement in implicit expressions of memory.

Complementing these results, recent work indicates that eyemovement-based memory effects may precede conscious awareness (e.g., Hannula et al., 2007; see also Hannula et al., 2012), and that activity in the hippocampus predicts these viewing effects even when explicit recognition has failed (Hannula and Ranganath, 2009). In these experiments (Hannula et al., 2007; Hannula and Ranganath, 2009), participants studied scene-face pairs and were tested with three-face displays superimposed on studied scenes. All three faces in each test display were studied, and on a subset of the trials, one of the faces had been paired with the scene during the encoding phase. When a preview of the scene was provided, disproportionate viewing of the associated face was evident approximately 500-750 ms after three-face display onset and preceded explicit recognition of that face by as much as $1000 \mathrm{~ms}^{2}$. This preferential viewing effect was evident within the same time frame regardless of the instructions provided at test, and even when it was counterproductive to view the associate. When amnesic patients with hippocampal damage were tested, viewing did not distinguish the associated face from the other two faces in the display, which provides evidence for relational memory impairment in these individuals. A follow-up investigation conducted with neurologically intact participants, which combined fMRI and eye tracking methods, showed that hippocampal activity differences during presentation of the scene cue predicted the viewing effect, even when analyses were limited to trials in which participants failed to identify the associated face in their explicit recognition responses (Hannula and Ranganath, 2009 see Figure 2). Activity differences associated with recognition accuracy were localized to lateral prefrontal cortex, and these differences, greater for correct than for incorrect responses, were correlated with those in the hippocampus during presentation of the three-face test displays. Like the findings reported by Ryan et al. (2000), such results implicate the hippocampus in relational memory retrieval, even without awareness. Consistent with the two-stage model of conscious

\footnotetext{
${ }^{2}$ Results of several experiments have shown that eye-movement-based memory effects precede explicit responses and that the time course of these effects is similar across investigations (cf. Hannula et al., 2012). While this consistency is remarkable, we cannot rule out the possibility that retrieved content may be accessible to awareness closer in time to the viewing effects than the findings suggest. To address this issue, we are currently conducting new experiments that will permit us to more precisely examine the temporal relationship between patterns of viewing and explicit recognition.
} 


\section{A Experimental Design}

Study Trials
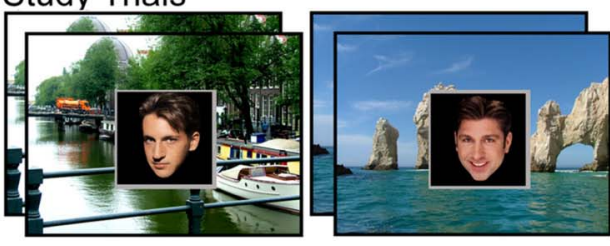

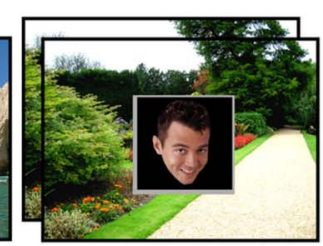

Test Trials

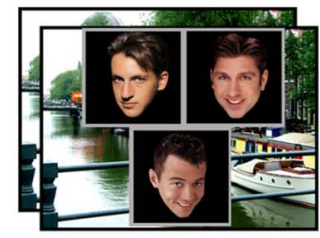

B

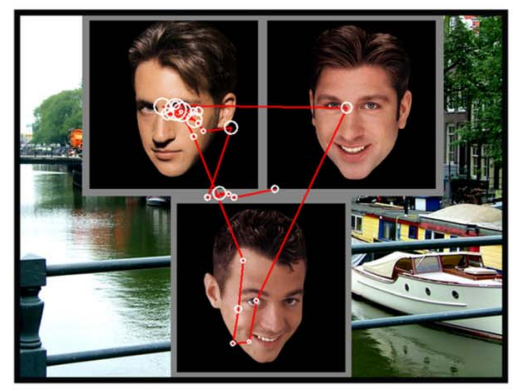

C

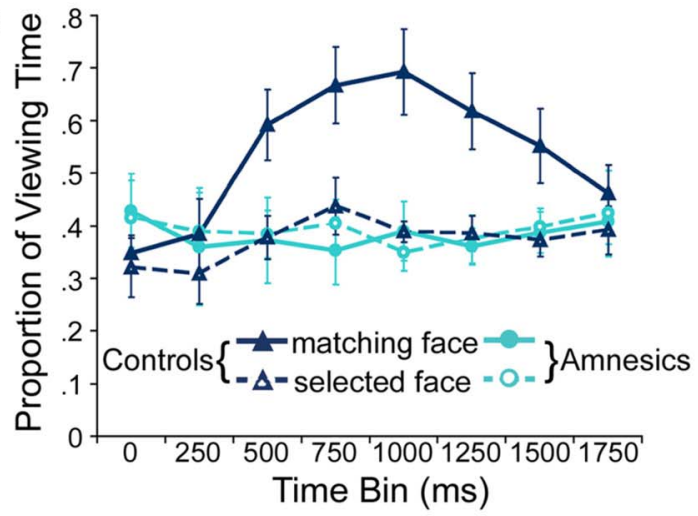

D Incorrect Trials: High Viewing > Low Viewing

L. Hippocampus

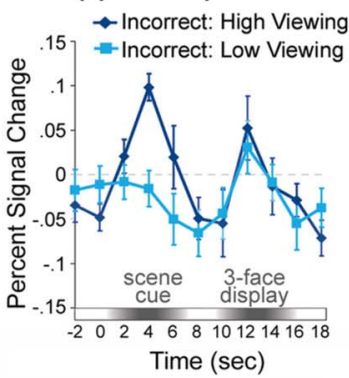

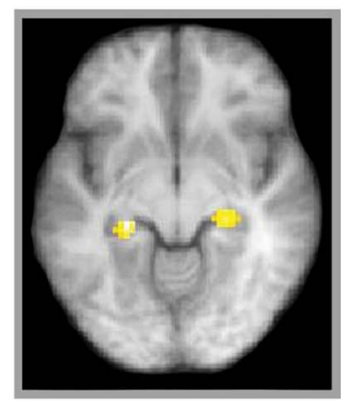

R. Hippocampus

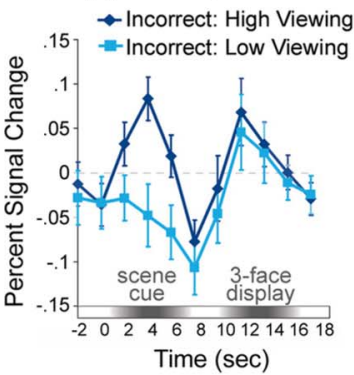

FIGURE 2 | Illustration of the basic paradigm and results from Hannula et al. (2007) and Hannula and Ranganath (2009). (A) Examples of scene-face pairs presented during the study trials, along with a single, associated test display in which the face on the left was the match (i.e., was the associate of the scene). Each test trial began with the presentation of a scene cue meant to prompt retrieval of the associated face. (B) Eye movements from a representative participant superimposed on the test display shown above. Fixations are indicated by white circles and the size of the circle was proportionate to the amount of viewing time directed to the fixated region. Transitions from one fixation to the next are indicated by red lines. (C) Proportion of total viewing time directed to correctly identified matching faces vs. faces that were merely selected from displays that did not contain a match broken down into $250 \mathrm{~ms}$ time bins following the onset of the three face test display. Neurologically intact control participants showed disproportionate viewing of the matching face just 500-750 ms after the faces were presented; no evidence of relational memory was evident in the eye movement behavior of amnesic patients. (D) Bilateral regions of the hippocampus for which BOLD signal was greater for incorrect trials during presentation of the scene cue when subsequent viewing of the match was high vs. when subsequent viewing of the match was low in college-age participants. Trial-averaged time courses extracted from the left and right hippocampal regions, respectively, show differences in BOLD signal between high and low viewing trials during presentation of the scene cue. This result illustrates hippocampal recruitment, even when explicit memory has failed. recollection, the results further suggest that successful explicit retrieval may depend upon interaction of the hippocampus with prefrontal regions.

\section{EVIDENCE FOR HIPPOCAMPUS-SUPPORTED LEARNING WITHOUT AWARENESS}

Hippocampal contributions to implicit memory have also been documented in investigations that give rise to learning that unfolds gradually over the course of several experimental trials or blocks. As was the case for the retrieval paradigms, evidence demonstrating hippocampus-supported implicit learning has been obtained in investigations using multiple research methods (e.g., fMRI, neuropsychological investigation) and across a variety of experimental tasks (i.e., contextual cueing, visual statistical learning, sequence learning, transitive inference), each of these are described in turn below.

Perhaps more than any other investigative approach, the contextual cueing paradigm, developed by Chun and Jiang 
(1998), has generated considerable debate about the existence of hippocampus-dependent implicit memory expression (e.g., Chun and Phelps, 1999; Manns and Squire, 2001; Greene et al., 2007; Preston and Gabrieli, 2008; Westerberg et al., 2011). Critically, this paradigm has also been subject to rigorous empirical investigation that has provided important insights into the nature of the memory representations that support performance (e.g., Jiang and Wagner, 2004; Brady and Chun, 2007). Although the proposal that learning in this task is truly implicit (e.g., Chun and Jiang, 2003) has been challenged, even skeptics have confirmed that contextual cueing is evident in the performances of "unaware" participants (Smyth and Shanks, 2008). Therefore, this extensive literature provides a strong context for evaluating conflicting evidence for and against hippocampal contributions to task performance absent concomitant awareness of the contingencies that support learning.

Participants in contextual cueing experiments search for a target (a rotated $\mathrm{T}$ ) among an array of distractors (rotated L's) and upon locating the target, make a button press response specifying whether it was rotated left or right. Over the course of several experimental blocks, a subset of the search arrays is presented repeatedly so that the distractors provide a stable spatial configuration predictive of target location; the remaining arrays are novel (i.e., presented just once) and have no predictive value (see Figure 3A). Results consistently show that the latency to locate the target decreases over the course of the experiment for both novel and repeated arrays (i.e., a general effect of skill learning), and that there is additional response time facilitation for repeated (vs. novel) arrays, which has been dubbed the contextual cueing effect. Based on early speculation that response time facilitation to repeated contexts depended ostensibly on the binding of target location to the global distractor configuration in which it was repeatedly embedded, it was proposed that contextual cueing should depend critically on structures in the MTL, particularly the hippocampus (Chun and Phelps, 1999). This proposal was notable because the seminal set of experiments documented the contextual cueing effect despite at-chance explicit recognition of repeated displays (Chun and Jiang, 1998).

In an effort to identify the neural substrates of contextual cueing Chun and Phelps (1999) conducted a neuropsychological experiment with MTL amnesic patients and a matched comparison group. Despite normal skill learning (i.e., decreased latency for novel and repeated arrays across experimental blocks), amnesic patients failed to demonstrate any additional facilitation for displays presented repeatedly over the course of the experiment (see Figure 3B). At first blush, this result seems strikingly similar to the one reported by Cohen and Squire (1980)amnesic patients show normal skill learning, but fail to benefit from repeated presentation of the same displays. The critical difference is that participants in the comparison group were rarely aware that some of the displays had been presented repeatedly. And more importantly, whether they reported having noticed these repetitions or not, they failed to distinguish repeated from novel displays when an explicit recognition test was administered. Based on these findings, it was concluded that "the hippocampal system mediates contextual (relational) encoding in humans, without having to evoke conscious memory processes" (Chun and Phelps, 1999; p. 846).

The results reported by Chun and Phelps (1999) were soon replicated in healthy participants under the influence of midazolam, a pharmacological agent that can induce a temporary amnesia (Park et al., 2004; see also Chun, 2005). This effect was particularly striking because the same (neurologically intact) participants who demonstrated intact contextual cueing absent the effects of midazolam were impaired when the drug was administered. One notable short-coming of both investigations was lack of anatomical specificity. While hippocampal atrophy was reported for three of four patients tested by Chun and Phelps (1999), one of whom was subsequently characterized as having damage limited to the hippocampus (Verfaellie et al., 2000), the remaining two had additional damage that extended beyond the hippocampus into adjacent MTL cortical structures. Results of a subsequent investigation (Manns and Squire, 2001) suggested that contextual cueing was only impaired for a subset of patients with extensive MTL lesions; those with damage limited to the hippocampus performed normally. This outcome challenges the claim that implicit expressions of learning in the contextual cueing task are mediated by the hippocampus. However, as indicated by Manns and Squire (2001), residual hippocampal tissue in patients with limited damage (i.e., $~ 32 \%$ average tissue loss with none greater than 50\%) may have contributed to intact contextual cueing in their investigation, and the patient identified as having limited hippocampal damage in the original work reported by Chun and Phelps (1999) failed to show a contextual cueing effect. Either way, the results are not easily accommodated by the declarative memory theory, as the evidence clearly points to a role for MTL cortical structures in unconscious learning and memory.

With the above caveats in mind, it is notable that contextual cueing performance seems to be supported by (at least) two qualitatively distinct memory representations (Jiang and Wagner, 2004). Originally, it was assumed that with repeated exposure to the array, the global geometric configuration of the distractors was learned and that contextual cueing was supported by a bound representation of this configuration to the target location in memory (Chun and Jiang, 1998). While this does indeed seem to be the case (Jiang and Wagner, 2004), evidence suggests that spatial relationships between individual distractors and the target can also support contextual cueing. Specifically, it was found that if a target appears repeatedly in the same location for two separate arrays, each with a different global configuration, contextual cueing was robust even on a transfer test in which half of the distractors from the first array were recombined with half from the second array, a manipulation that changed the global configuration of display elements (see Figure 3C). Hence, two representations seem to support contextual cueing: (1) a fused representation of the global array configuration that, by some views (e.g., relational memory theory and Henke's processing model), could be supported by structures in the parahippocampal region and (2) a representation of spatial relationships between the target and individual distractors that can give rise to flexible memory expression when novel, recombined displays are presented. One possibility then is that spared performance on the contextual cueing task in hippocampal amnesia reflects preserved 

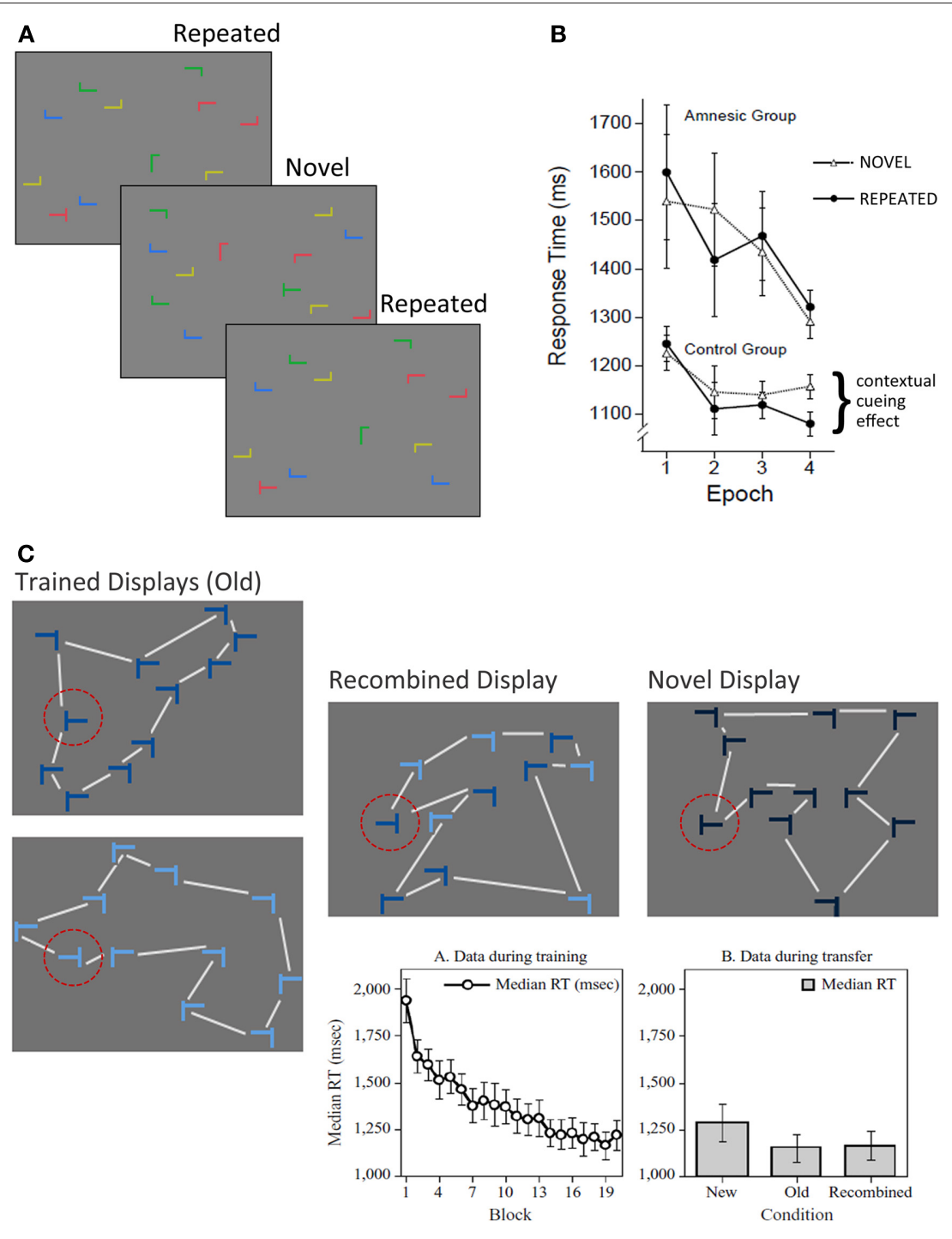

FIGURE 3 | The contextual cueing task. (A) Illustration of the basic contextual cueing paradigm. Participants attempt to locate a target (i.e., a rotated T) from among an array of distractors (i.e., rotated L's) as quickly as possible upon display presentation. A subset of the displays are repeated several times over the course of the experiment. (B) Illustration of the results from Chun and Phelps (1999). Both amnesic patients and controls show improved skill learning (i.e., faster target identification) over the course of the experiment, but patients show no evidence for contextual cueing.

(C) Illustration of conditions used in the modified version of the contextual cueing task that was used to examine transfer effects, and was developed by Jiang and Wagner (2004). Trained displays were seen during learning, and were also used to create recombined displays. Color coding (shades of blue) was not used in the experiment, but is meant to illustrate how the recombined display was created. Half of the elements in the display were from one trained display, the remainder were from the other. The lines connecting the display elements are meant to illustrate the differences in overall gestalt of the display configuration, and were not present during testing. Notice that the shape of the global configuration is different for the recombined display than for both trained displays. Novel displays controlled for any facilitation in responding that might be due to the target location alone. The standard skill learning effect is illustrated in the graph on the left. Effects of transfer are illustrated in the graph on the right. The time required to locate and respond to a target was not different for recombined and old displays, and both of these display types elicited faster responses than novel displays. Such results provide evidence for flexible transfer of learning from trained displays to recombined displays. [Figure 3B reprinted by permission from Macmillan Publishers Ltd; http://www.nature.com/; Figure 3C, graphs, reprinted with kind permission from Springer Science+Business Media.]. representation of global configuration in the parahippocampal region. To the extent that the two documented representations co-exist, one (i.e., the fused associative representation) might compensate for the other (i.e., the flexible relational representation) in cases of hippocampal damage. Whether and when in the course of learning these representations emerge remains to be determined, but the suggestion has been made that early learning might reflect spatial relationships between targets and individual distractors, and that representations of global configuration develop more slowly (Jiang and Wagner, 2004).

Much like the neuropsychological work, results from recent fMRI investigations attempting to identify the neural substrates of contextual cueing have been mixed (Greene et al., 2007; Preston and Gabrieli, 2008; Westerberg et al., 2011). While one 
study reported implicit, facilitation-related activity differences in left posterior hippocampus and left parahippocampal cortex (Greene et al., 2007), others found that hippocampal activity differences were correlated with explicit recognition of repeated displays (Preston and Gabrieli, 2008; Westerberg et al., 2011). Notably, those studies failing to show implicit hippocampal differentiation included only trial number (or epoch) and stimulus type (i.e., novel vs. repeated arrays) as parametric factors in the reported fMRI analyses. Greene et al. (2007) likewise did not find implicit hippocampal effects with just these two factors, but recognized that not all repeated arrays showed robust response time facilitation. Including reaction time as a factor in subsequent analyses had two consequences: (1) hippocampal differentiation was revealed as an interaction of stimulus type and reaction time in the left posterior hippocampus, such that the effect was only evident for repeated arrays with greater response time facilitation; and (2) the decrease in unexplained variance allowed the detection of a main effect of stimulus type located bilaterally in the posterior hippocampus. It is, therefore, advised that future investigation of contextual cueing incorporate this approach.

As stated above, some neuroimaging studies have revealed hippocampal activity differences associated with explicit recognition of repeated displays (Preston and Gabrieli, 2008; Westerberg et al., 2011). In one of these investigations 13 of 23 participants performed above chance on the recognition test administered after learning (Preston and Gabrieli, 2008); using the same methods, Greene et al. (2007) reported at-chance recognition among their participants. Such differences in behavioral outcome are difficult to explain, but may reflect slight modification of instruction, and/or differences in strategy adopted by the participants to perform the task. Indeed, changes in strategy, based for example on encouragement to guess, can improve recognition performance, but these performance improvements do not always reflect conscious retrieval processes (Voss et al., 2008; Voss and Paller, 2009, 2010). The remaining study that reported hippocampal activity differences linked to awareness used a procedure in which participants were instructed about repetitions and told to use this information to their advantage while performing the task (Westerberg et al., 2011). Clearly, further investigation is needed to better pin down the variables that drive hippocampal recruitment in contextual cueing. Aside from incorporating the analysis technique described above, future work might also examine whether and how structures in the MTL, and especially the hippocampus, contribute to successful (flexible) transfer (as reported by Jiang and Wagner, 2004) when two displays associated with the same target location are used to create a novel configuration. The expectation here would be that activity differences in the hippocampus would support facilitated responding to recombined displays on the transfer test.

Response time facilitation in the contextual cueing paradigm derives from the presentation of displays in which target location is predicted by the simultaneous presentation of an invariant context. As such, there is no requirement to integrate display elements across time. An alternative approach that has been used to investigate incidental learning involves manipulation of the transitional probabilities among individual items seen repeatedly over the course of an experiment or an experimental block. A subset of these items are presented in a repeated sequence so that one item has the potential to reliably predict, or cue, the appearance of another (e.g., Face A always precedes Scene A); the remaining items are also repeated, but have no predictive value.

Recent work suggests that the hippocampus is engaged by these statistical learning paradigms, and is sensitive to the temporal co-occurrence of items embedded in repeated sequences (Turk-Browne et al., 2008, 2010). In one of these investigations, the hippocampus was the only region that showed reliably enhanced activity during the presentation of the first element in a "paired" set, which suggests that it may be involved in the process of anticipating, or calling to mind, the (temporally) associated element as learning proceeds. This result resembles findings described earlier, in which hippocampal activity differences during presentation of a scene cue predicted viewing of the associated face (Hannula and Ranganath, 2009). In both cases, presentation of a cue may elicit retrieval of relationally bound memory representations, perhaps by way of pattern completion processes mediated by the hippocampus (Hannula et al., 2007). Importantly, results indicated that these effects reflect implicit learning because participants were unaware of repeated patterns when a post-test awareness questionnaire was administered; however, performance on a post-learning recognition test revealed greater than chance discrimination of sequentially presented pairs vs. foils. While a skeptic might argue that this result implicates conscious processes in learning, recent work (mentioned briefly above) has suggested that the relationship between recognition performance and explicit memory might not be so straightforward. Specifically, it has been found that when participants are encouraged to guess, implicit memory can support successful forced-choice responding (cf. Voss and Paller, 2010). Clearly, this is an important issue that will be a source of much future investigation, and is something to consider with respect to the interpretation of results from post-learning recognition tests as these are often administered with instructions that encourage participants to guess. Borrowing from Voss and Paller (2010), researchers could incorporate confidence judgments that include a "guess" response in future work as a first step toward addressing the possibility that correct recognition on awareness tests reflects accurate guessing.

As discussed earlier, representational flexibility is considered a key property of hippocampus-dependent memory representations. This flexibility underscores demonstrations of explicit memory, and is made possible because the complex relationships mediated by the hippocampus are necessary for disambiguation (pattern separation) and for the generativity of cued recall (pattern completion; cf. Norman and O'Reilly, 2003). As suggested above, certain implicit tasks may necessarily involve the hippocampus if the associated task demands require pattern completion or pattern separation. One such task is the serial reaction time task (SRTT), which is performed implicitly, depends upon both pattern separation and pattern completion, and requires contributions of the hippocampus and surrounding MTL cortical structures to support performance.

In the SRTT, a series of stimuli appear on a screen and each unique stimulus requires a distinct response (e.g., a particular 
button press) from the participant. Embedded in the series of stimuli are certain repeating sequences, and when these sequences are short, unambiguous, and occur with enough regularity, participants show faster reaction time for items cued by the sequence than for randomly occurring items (cf. Reed and Johnson, 1994). Based on the nature of this facilitation, and on findings of performances among amnesic patients that are comparable to those of controls, it has been said that this is a clear example of procedural learning. However, longer sequences may be used wherein the predictive value of multiple items is Markovian. In the simplest case, consider the sequence A-D-C-D-A-B-D-B. In this case, the predictive value of $\mathrm{D}$ is ambiguous as it precedes $\mathrm{A}, \mathrm{B}$, and $\mathrm{C}$ equally often. In order to make correct predictions for items following $\mathrm{D}$, it is necessary to keep track of the item prior to $\mathrm{D}$. That is, A-D unambiguously predicts $\mathrm{C}$, while C-D unambiguously predicts $\mathrm{A}$, and $\mathrm{B}-\mathrm{D}$ unambiguously predicts $\mathrm{B}$.

Critically, in this version of the SRTT performance is not associated with awareness of the repeating sequence, amnesic patients are impaired (Curran, 1997), and the impairment is amplified as more items are required for the sequence to be predictive (e.g., Shanks et al., 2006). While it may be difficult to draw definitive conclusions about the involvement of the hippocampus based on the data from amnesic patients, several lines of converging evidence make the case stronger. First, normal-memory participants under the influence of systemic diazepam, which induces a temporary amnesia, showed impaired performance on the SRTT comparable to that of organic amnesics (Shanks et al., 2006). Second, fMRI reveals that normal memory participants show significantly greater activation in the hippocampus and surrounding MTL cortical structures while performing the SRTT when there are higher-order sequences (like those described above) embedded in the stimulus set (Schendan et al., 2003a,b). Together, these results provide yet another compelling demonstration of hippocampus-mediated facilitation on a task that is performed without awareness and requires flexible representation of relationships among items.

One final well-studied implicit learning task that requires relational flexibility (i.e., pattern separation and pattern completion) is the transitive inference (TI) task. The TI task is of particular interest because it requires both induction and deduction, and allows the inference of unstudied relationships. Thus it provides insights into how we may use past learning to model complex contingencies sufficient for prediction under novelty. Indeed, any discussion of relational flexibility must be predicated on the notion that the fundamental utility of memory is to improve our ability to negotiate future events (cf. Schacter et al., 2008).

In a typical TI experiment, participants are trained to make certain pairwise discriminations. For instance if A and B are presented simultaneously, participants would learn by trial and error to choose A (hereafter abbreviated A $>$ B). Such items are referred to as premise pairs, and a series of overlapping premise pairs is acquired by the participant over the course of several trials (e.g., $\mathrm{A}>\mathrm{B}, \mathrm{B}>\mathrm{C}, \mathrm{C}>\mathrm{D}, \mathrm{D}>\mathrm{E}, \mathrm{E}>\mathrm{F}$ ). It is possible to maintain the acquired information as five distinct pieces of information, or alternatively, to integrate it into a more global representation (i.e., $\mathrm{A}>\mathrm{B}>\mathrm{C}>\mathrm{D}>\mathrm{E}>\mathrm{F}$ ). Note that this global representation requires fewer operations, but also contains information not trained-namely, relationships between non-adjacent pairs. This can be tested by asking participants to make decisions about nonstudied pairings such as $\mathrm{B}$ ? D, B?E, and $\mathrm{C}$ ?E. Correctly choosing $\mathrm{B}>\mathrm{D}, \mathrm{B}>\mathrm{E}$, and $\mathrm{C}>\mathrm{E}$ is evidence that participants have ordered the items and have made correct inferences (note that pairings with $\mathrm{A}$ or $\mathrm{F}$ require no inferences as these are always and never correct, respectively).

Interestingly, participants can perform well above chance on inferred items in the absence of explicit strategies (e.g., Greene et al., 2001). That is, while participants are aware they have learned the premise pairs, they do not deliberately infer novel relations and are generally unaware that they have made an inference, or that it was possible to do so. In addition, performance on the TI task has been shown to depend critically on the hippocampus from converging evidence as fMRI data shows that success on the TI task depends on activity differences in the hippocampus during both study and test (Greene et al., 2006), and hippocampal amnesics are not capable of doing the task (Smith and Squire, 2005).

There is some concern about how awareness is assessed in this paradigm. Indeed, it has been asserted that successful inference is related to task awareness (Smith and Squire, 2005). However, Greene et al. (2001) have shown that a brief training period leads to high inference without awareness, while extended training leads to nearly every participant becoming task-aware. A close examination of the methods used by Smith and Squire (2005) reveals that their conclusion that performance and awareness are related is entirely attributable to overtraining (see Greene, 2007). Others are concerned that implicit inference may be an example of pseudo-inference (e.g., Frank et al., 2003). According to this argument, the closer an item is to an endpoint of the sequence, the stronger is its reinforcement value. The first item is never wrong, and thus has the highest reinforcement value, the last item is never right, and therefore has the lowest reinforcement value; intermediate items obtain intermediate values according to their proximity to the end items. Thus the $\mathrm{B}>\mathrm{D}$ choice can be made without true inference by simply comparing the relatively higher positive weight of B to D. Even if this pseudo-inference account is correct, all of the direct evidence implicates the hippocampus as necessary for success in this task. More importantly, a similar inference task has been devised which has no endpoints, and therefore cannot be solved with a differential weighting strategy (see Figure 4; Leo and Greene, 2008; adapted from Bunsey and Eichenbaum, 1996). As with similar TI studies, participants performed well above chance on all inferences and few exhibited any sign of explicit strategy or knowledge; in fact, most were surprised to learn in debriefing that the items at test had not been studied.

\section{EVIDENCE FOR HIPPOCAMPUS-SUPPORTED ENCODING WITHOUT AWARENESS}

As has been discussed, models of hippocampal function diverge with respect to whether or not conscious apprehension of stimulus input is considered necessary during encoding (e.g., Moscovitch, 1992; Henke, 2010). In line with those who claim that consciousness is critical, the idea that information presented subliminally can support subsequent memory expression seems to 


\section{Training set 1}

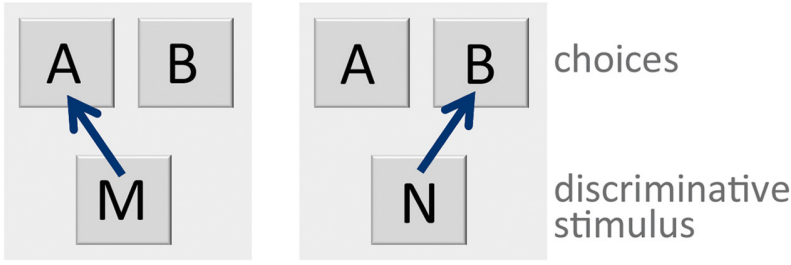

\section{Training set 2}
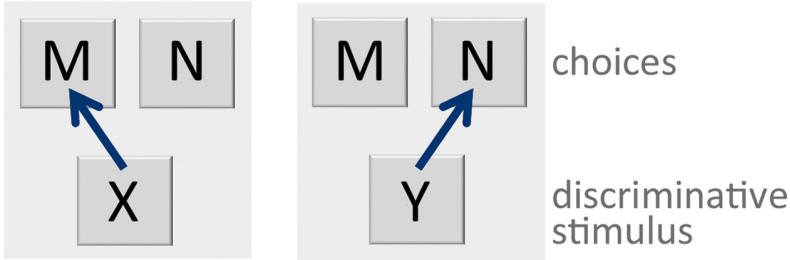

\section{Test for transitivity}

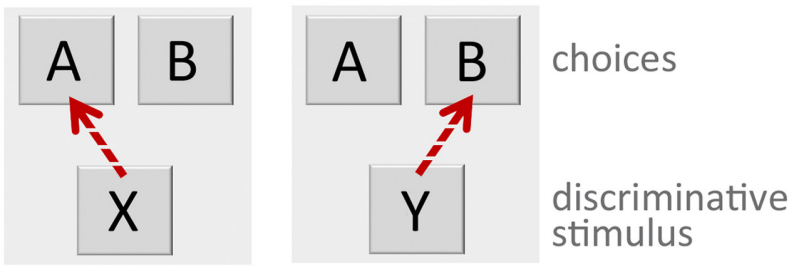

FIGURE 4 | Illustration of the modified transitive inference paradigm that cannot be solved via pseudo-inference. In this version of the task, three items (e.g., faces, objects) appear on the screen in an upside down triangle on each trial. Participants are instructed to choose one of the top two items via button-press, and are told that the bottom item determines which of the remaining two items is correct. Two sets of these trial types are developed for training. As illustrated in the figure, when " $\mathrm{M}$ " is presented on the bottom (in training set 1) participants learn to choose " $A$ ", and when " $X$ " is presented on the bottom (in training set 2) participants learn to choose "M". Once criterion learning has been achieved on all of displays presented during learning, the test for transitivity is administered. In this case, participants have not learned (i.e., were not trained on) the relationships among display elements, but must make an inference. Evidence for inference is obtained when, for example, participants choose " $A$ " when " $X$ " is the discriminative stimulus. In this case " $X$ " and " $A$ " are indirectly linked via " $M$ ". As indicated in the text, this version of the TI task has no endpoints and cannot be solved using pseudo-inference.

go against the grain of conventional findings that document the beneficial influence of deep or elaborative encoding on memory performance (Craik and Lockhart, 1972). More generally, in the implicit perception literature, questions about the extent to which subliminal information can be processed perceptually and especially conceptually (i.e., semantically) have incited much debate (e.g., Holender, 1986; Dulany, 1997; Reingold, 2004); such disagreement has led to the development of very strict criteria for demonstrating that stimulus input was in fact completely masked from awareness before claims of implicit processing can be made (see Hannula et al., 2005 for review). Having been informed by this debate, and the methodological constraints that have been put in place as a result, Henke and colleagues (Henke et al., 2003a,b; Degonda et al., 2005; Duss et al., 2011) have developed a program of fMRI research that seems to pose a significant challenge to staunch adherents of the view that the hippocampus cannot or does not contribute to encoding processes when stimulus input is not consciously accessible.

In these experiments, subliminal encoding entails presentation of several face-occupation name pairs that are flashed briefly and sandwiched in between a set of visual pattern masks that render the pair invisible (see Figure 5A). An incidental memory test that entails supraliminal (i.e., visible) presentation of the faces, absent the associated occupation name, is then administered following a delay (e.g., $5 \mathrm{~min}$ )—that any effect of implicit memory can be identified with a delay in place is itself worthy of comment, as effects of implicit perception on performance are thought to be relatively short-lived (Wolfe, 1999; see also Simons et al., 2006). Nonetheless, evidence for implicit memory has now been successfully documented in several of these experiments, using a wide variety of tasks and measures of performance. For example, when instructed at test to guess the occupational category (i.e., artist or academic) or occupationrelated characteristics (e.g., long or short education) of the individual depicted by the face, response times were faster for correct than for incorrect guesses (see Figure 5B; Henke et al., 2003b; see also Duss et al., 2011). In addition, results show that participants can classify these faces according to occupationrelated characteristics with above-chance accuracy (Duss et al., 2011). Based on the processing requirements of these tasks, which require flexible representation of relationships among items, one might expect the hippocampus to be recruited during subliminal encoding and/or incidental retrieval of face-occupation name pairs. The results do not disappoint, as activity differences relative to respective control conditions have been observed in the anterior hippocampus (and perirhinal cortex) not only during the supraliminal retrieval phase ${ }^{3}$, but also during subliminal encoding (Henke et al., 2003a,b). Perhaps more compelling, hippocampal (and perirhinal) engagement was correlated with response time differences on the incidental test of memory (see Figure 5C).

The basic paradigm described above was modified in subsequent investigation (Degonda et al., 2005) so that the subliminal encoding phase was followed by visible encoding prior to testing. Such manipulations provided more opportunity to investigate influences of implicit exposure on subsequent behavior and brain activity. In three separate experiments, the occupation name paired with a given face during visible encoding was either from the same category (e.g., artist: photographer $\rightarrow$ guitarist), the other category (e.g., artist: poet $\rightarrow$ academic: professor), or was exactly the same occupation (i.e., painter $\rightarrow$ painter) as that associated with that face during subliminal encoding. Under these circumstances, it was found that the ease with which participants could imagine the individual in the associated occupation during the second, visible encoding phase was significantly reduced in the incongruent condition. Moreover, results from the test phase

\footnotetext{
${ }^{3}$ Note that while the stimuli were visible (i.e., supraliminal) during the retrieval phase, the retrieval process was necessarily implicit because faceoccupation pairs had been encoded without awareness (i.e., subliminally).
} 


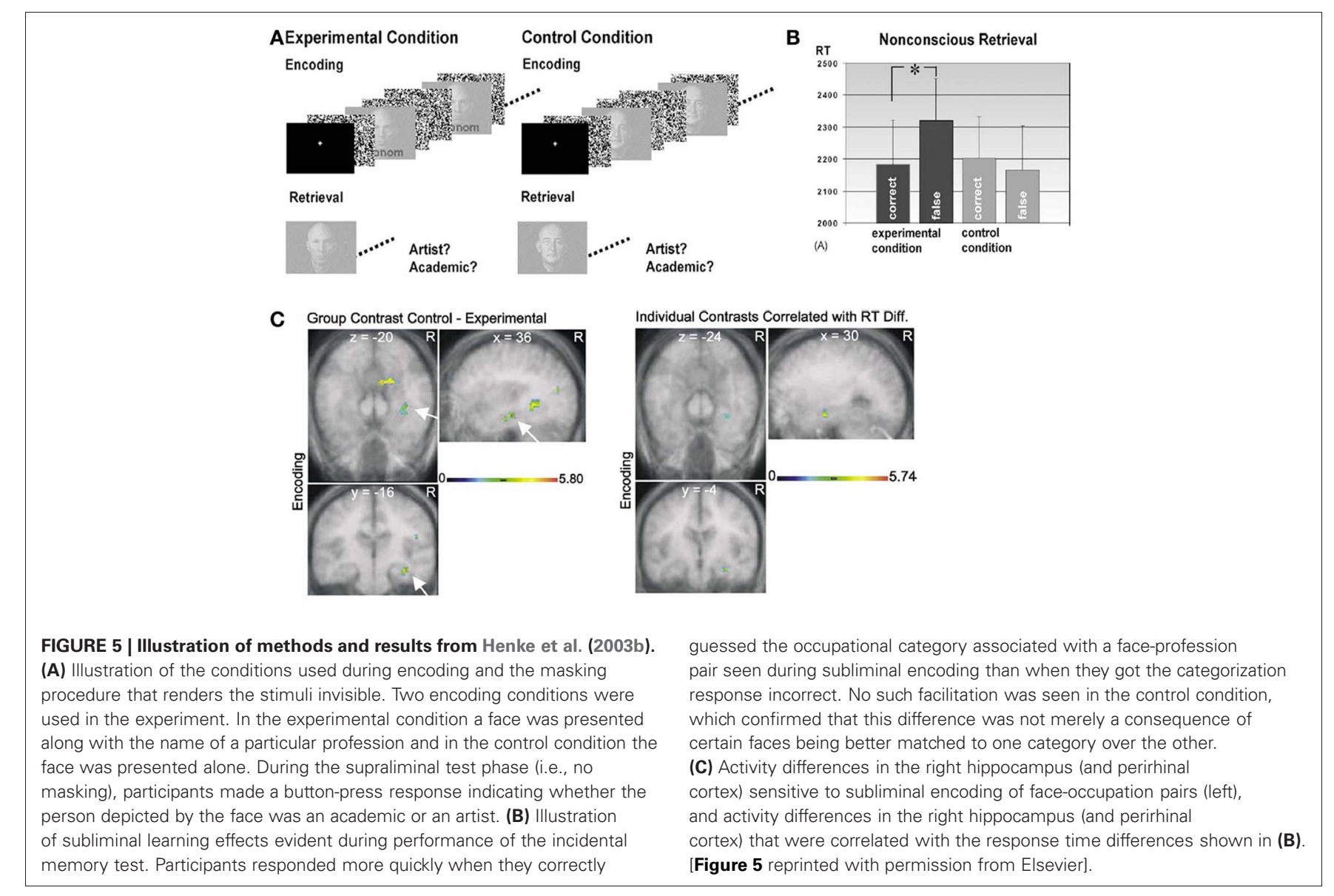

showed that correct identification of the occupational category for a given face was reduced for all three conditions relative to a control in which the face had been paired with a nonsense word during subliminal encoding. As such, there were several converging pieces of evidence for successful acquisition of subliminally encoded content. Consistent with the findings reported in earlier studies by the group, hippocampal activity was evident during subliminal encoding in all three experiments, and greater hippocampal recruitment was positively correlated with the reported deficit in explicit retrieval for both the incongruent and congruent conditions. Such results are perhaps surprising, but as they have been consistently replicated, it seems that models of hippocampal function will need to account for them. Future work might also examine whether or not there are differences in how information is conveyed to the hippocampus when stimuli are presented subliminally. To our knowledge this question has not yet been addressed, but similar issues have been a source of on-going investigation in the emotion literature. The dominant view, which has not gone unopposed (cf. Pessoa and Adolphs, 2010), attributes rapid implicit processing of affective visual stimuli to a short latency subcortical pathway that bypasses visual cortex and conveys information directly to the amygdala by way of the superior colliculus and the pulvinar. This research, and the ensuing debate, will likely inform similar questions about hippocampus-supported subliminal memory.

\section{AT THE TIPPING POINT: HIPPOCAMPAL FUNCTION EXTENDS BEYOND CONSCIOUS MEMORY}

As has been conveyed in the preceding section, there is now considerable evidence from experiments conducted with a range of methodological techniques that implicates the hippocampus in memory without awareness. Such findings have been documented in investigations that examined implicit retrieval, implicit learning, and implicit encoding. Perhaps most surprising is the evidence for hippocampus-mediated implicit (and in the examples described above, subliminal) encoding. These experiments, which borrow substantially from lessons learned in the implicit perception literature about how best to eliminate awareness, have been replicated several times, and are not easily accommodated by models of hippocampal function that place a premium on conscious apprehension of encoded content (e.g., Moscovitch, 1992). The results are, however, in line with the view that the hippocampus is critically involved in binding together inter-item or item-context relationships that can then give rise to flexible memory expression (e.g., Cohen and Eichenbaum, 1993; Henke, 2010). Indeed, even a cursory comparison of the experiments reported above reveals quite readily that what these tasks have in common is the requirement for relational memory binding and representation. Additional information as to what exactly this might entail is provided by Olsen and colleagues (this issue) who propose that the specific role of the hippocampus may be to continuously bind the elements of experience and to compare 
representations retained in memory to current perceptual input. One result of this continuous binding and comparison process is that novel information can be integrated into existing relational memory representations. Consistent with the evidence reviewed here, Olsen and colleagues contend that both of these processes can proceed in the absence of awareness and that the resulting relational memory representation need not be consciously accessible.

To date, the bulk of the evidence in support of hippocampusmediated implicit memory seems to have come from investigations that involve temporally extended (i.e., multiple trial) learning, which according to some views, should not depend upon the hippocampus (Henke, 2010). Importantly, Henke (2010) does indicate that there may be exceptions to this rule. Semantic memories, for example, may depend initially on the hippocampus despite repeated exposure, and concessions are made for "rare" episodic memories that retain their flexibility with the passage of time. As there are now several findings that implicate the hippocampus in implicit learning that develops gradually over the course of several experimental trials, further specification of the model describing exactly when and how the hippocampus would be involved in such learning seems warranted. Altogether, the results are perhaps most problematic for those who have retained a strict interpretation of the declarative memory theory (e.g., Squire, 2004), in which the hippocampal system is said to mediate only those memories that are amenable to conscious report (i.e., can be "declared"). While the relational memory theory shares the view that MTL structures (including the hippocampus) support declarative memory (cf. Cohen and Eichenbaum, 1993), proponents of this view do not take a hard line on the consciousness issue (e.g., Cohen et al., 1997; Ryan and Cohen, 2003). One possibility then is that declarative memory is perhaps best characterized as a subset of relational memory, and as an especially good example of relational memory when studies are conducted with human subjects.

The extant possibility is that the hippocampus is necessary, but not sufficient for conscious recollection. Indeed, it has been proposed that other regions, namely structures in the prefrontal cortex and parietal cortex (Cohen et al., 1997; Moscovitch, 2008), interact with the hippocampus and in so-doing, contribute to the process of conscious recollection. That this may indeed be the case is suggested by converging evidence implicating the prefrontal cortex in facilitating top-down selection and organization of retrieved content, as well as updating features relevant to the demands of on-going retrieval attempts (see Shimamura, 2011 for review). The literature proposing a role for the parietal cortex in memory retrieval is relatively recent, but there is now a considerable amount of evidence implicating posterior parietal cortex (PPC) in particular aspects of memory retrieval. Interestingly, activity differences in PPC show that this brain region is responsive not only to correct memory decisions, but also to false alarms, which suggests that it may play an especially important role in subjective experience (e.g., Wheeler and Buckner, 2003). Several recent theoretical perspectives (see Shimamura, 2011 for review) have been advanced in an attempt to explain the role of the PPC in memory. Across perspectives, this region has been implicated in the process of accumulating/monitoring retrieved content (Wagner et al., 2005), acting as an episodic buffer (Vilberg and Rugg, 2008), and directing attention to retrieved content (Cabeza et al., 2008; Ciaramelli et al., 2008). Among these perspectives, the "attention to memory model" (Cabeza et al., 2008; Ciaramelli et al., 2008) has perhaps provided the most detailed account of how the PPC might interact with MTL and PFC regions during retrieval. Specifically, it is proposed that dorsal PPC might interact with (dorsolateral) PFC to mediate top-down, effortful, retrieval processes and that ventral PPC might interact with MTL structures in a bottom-up fashion. In this case, attention is captured by content that has been retrieved by MTL structures, including the hippocampus. More precise specification of how exactly these structures might interact requires further investigation, as does differentiating among competing views (see also Shimamura, 2011 for another proposal), but these efforts do provide a starting point for identifying when and how other brain regions might contribute to memory retrieval and the associated experience of conscious recollection.

Finally, it is worth considering which empirical approaches are most likely to yield success in endeavors to further explore the role of the hippocampus in unconscious encoding and/or subsequent expression of memory. In some cases, it is preferable to design a task that precludes knowledge of the link between task performance and memory. Devising such tasks can be particularly difficult because the complexity of the task demands often favor explicit strategies and because any overtraining can impel awareness of the contingencies that support performance (cf. Greene, 2007). Tasks already known to require hippocampal involvement can sometimes be designed to minimize the likelihood of awareness, but in designing such tasks, several factors should be considered. Such factors include, but are not limited to: (1) maintaining the shortest possible task exposure, especially avoiding time for rumination; (2) use of brief stimulus exposure; (3) use of novel stimulus materials; (4) use of more stimulus items than can be deliberately memorized; (5) designing tasks that cannot be supported by verbal strategies; and in this case, (6) avoiding any hint whatsoever that the task involves learning or memory. On the other hand, it is critical to consider that one can lessen task awareness without entirely eliminating its use; as such, one runs the risk that explicit strategies might be used but not detected. The approach adopted by Henke and colleagues (e.g., Duss et al., 2011), which makes use of masking procedures to render stimulus input invisible, offers promise in this regard. As an alternative to the above approach, one might opt to combine direct tests (e.g., forced-choice recognition tests) with additional measures that are capable of revealing effects of memory in the absence of awareness. Approaches that have a documented track record along these lines include, but are not limited to, concomitant acquisition of sensitive indirect measures (e.g., eye movements) with behavioral testing (see Hannula et al., 2010 for review) and incorporation of methods that facilitate, and have the potential to reveal, accurate guessing (cf. Voss and Paller, 2010). Use of these methods acknowledges that memory tests are rarely process pure, and may permit investigators to more effectively tease apart the contributions made by explicit and implicit memory to performance. 
In sum, the existence of implicit, hippocampus-dependent tasks has eluded scientists for decades because such tasks are difficult to design and can readily trigger awareness-consequently, we are near the beginning of this endeavor. However, as reviewed here, we now have a solid starting point as several lines of

\section{REFERENCES}

Althoff, R. R. (1998). Eye-MovementBased Memory Assessment: The Use of Eye Movement Monitoring as an Indirect Measure of Memory. Unpublished doctoral dissertation, University of Illinois at UrbanaChampaign, Urbana.

Althoff, R. R., and Cohen, N. J. (1999). Eye-movement based memory effect: a reprocessing effect in face perception. J. Exp. Psychol. 25, 997-1010.

Althoff, R. R., Maciukenas, M., and Cohen, N. J. (1993). Indirect assessment of memory using eye movement monitoring. Abstr. Soc. Neurosci. 19, 439.

Badgaiyan, R. D., Schacter, D. L., and Alpert, N. M. (2003). Priming of new associations: a PET study. Neuroreport 14, 2475-2479.

Beck, M. R., Peterson, M. S., and Angelone, B. L. (2007). The roles of encoding, retrieval, and awareness in change detection. Mem. Cognit. $35,610-620$.

Bowers, J. S., and Schacter, D. L. (1990). Implicit memory and test awareness. J. Exp. Psychol. Learn. Mem. Cogn. 16, 404-416.

Brady, T. F., and Chun, M. M. (2007). Spatial constraints on learning in visual search: modeling contextual cueing. J. Exp. Psychol. Hum. Percept. Perform. 33, 798-815.

Bruner, J. S. (1969). "Modalities of memory," in The Pathology of Memory, eds G. A. Talland and N. C. Waugh (New York, NY: Academic Press), 253-259.

Bunsey, M., and Eichenbaum, H. (1996). Conservation of hippocampal memory function in rats and humans. Nature 379, 255-257.

Cabeza, R., Ciarmelli, E., Olson, I. R., and Moscovitch, M. (2008). Parietal cortex and episodic memory: an attentional account. Nat. Rev. Neurosci. 9, 613-625.

Carlesimo, G. A., Perri, R., Costa, A., Serra, L., and Caltagirone, C. (2005). Priming for novel between-word associations in patients with organic amnesia. $J$. Int. Neuropsychol. Soc. 11, 566-573.

Cermak, L. S., Blackford, S. P., O'Connor, M., and Bleich, R. P. (1988a). The implicit memory ability of a patient with amnesia due to encephalitis. Brain Cogn. 7, 145-156.

Cermak, L. S., Bleich, R. P., and Blackford, S. (1988). Deficits in the implicit retention of new associations by alcoholic korsakoff patients. Brain Cogn. 7, 312-323.

Chun, M. M. (2005). Drug-induced amnesia impairs implicit relational memory. Trends Cogn. Sci. 9, 355-357.

Chun, M. M., and Jiang, Y. (1998). Contextual cueing: implicit learning and memory of visual context guides spatial attention. $\operatorname{Cog} n$. Psychol. 36, 28-71.

Chun, M. M., and Jiang, Y. (2003). Implicit, long-term spatial contextual memory. J. Exp. Psychol. Learn. Mem. Cogn. 29, 224-234.

Chun, M. M., and Phelps, E. A. (1999). Memory deficits for implicit contextual information in amnesic subjects with hippocampal damage. Nat. Neurosci. 2, 844-847.

Ciaramelli, E., Grady, C. L., and Moscovitch, M. (2008). Top-down and bottom-up attention to memory: a hypothesis (AtoM) on the role of the posterior parietal cortex in memory retrieval. Neuropsychologia 46, 1828-1851.

Cohen, N. J. (1984). "Preserved learning capacity in amnesia: evidence for multiple memory systems," in Neuropsychology of Memory, eds L. R. Squire and N. Butters (New York, NY: Guilford Press), 83-103.

Cohen, N. J., and Eichenbaum, H. (1993). Memory, Amnesia, and the Hippocampal System. Cambridge, MA: The MIT Press.

Cohen, N. J., Poldrack, R., and Eichenbaum, H. (1997). Memory for items and memory for relations in the procedural/declarative memory framework. Memory 5, 131-178.

Cohen, N. J., and Squire, L. R. (1980). Preserved learning and retention of a pattern-analyzing skill in amnesia: dissociation of knowing how and knowing that. Science 210, 207-210.

Corkin, S. (1968). Acquisition of motor skill after bilateral medial temporal lobe excision. Neuropsychologia 6, 255-265. S. (1972). Levels of processing: a framework for memory research.
Craik, F. I. M., and Lockhart, R.

converging evidence have implicated the hippocampus in unconscious memory. Unraveling the Gordian knot of hippocampal function will undoubtedly require a great deal more empirical instances than are presently available in the literature, making this line of work ripe for further investigation.

J. Verb. Learn. Verb. Behav. 11, 671-684.

Curran, T. (1997). Higher-order associative learning in amnesia: evidence from the serial reaction time task. J. Cogn. Neurosci. 9, 522-533.

Curran, T., and Schacter, D. L. (1997) Implicit memory: what must theories of amnesia explain? Memory 5, $37-47$.

Degonda, N., Mondadori, C. R. A., Bosshardt, S., Schmidt, C., Boesiger, P., Nitsch, R. M., Hock, C., and Henke, K. (2005). Implicit associative learning engages the hippocampus and interacts with explicit associative learning. Neuron 46, 505-520.

Dew, I. T. Z., and Cabeza, R. (2011). The porous boundaries between explicit and implicit memory: behavioral and neural evidence. Ann. N.Y. Acad. Sci. 1224, 174-190.

Dulany, D. E. (1997). "Consciousness in the explicit (deliberative), and implicit (evocative)," in Scientific Approaches to Consciousness, eds. J. D. Cohen and J. W. Schooler (Hillsdale, NJ: Carnegie Mellon Symposia on cognition), 179-212.

Duss, S. B., Oggier, S., Reber, T. P., and Henke, K. (2011). Formation of semantic associations between subliminally presented face-word pairs. Conscious. Cogn. 20, 928-935.

Eichenbaum, H., and Bunsey, M. (1995). On the binding of associations in memory: clues from studies on the role of the hippocampal region in paired associate learning. Curr. Dir. Psychol. Sci. 4, 19-23.

Eichenbaum, H., and Cohen, N. J. (2001). From Conditioning to Conscious Recollection: Memory Systems of the Brain. Oxford: Oxford University Press.

Eichenbaum, H., Otto, T., and Cohen, N. J. (1994). Two component functions of the hippocampal memory system. Behav. Brain Sci. 17, 449-517.

Erikson, C. A., and Desimone, R. (1999). Responses of macaque perirhinal neurons during and after visual stimulus association learning. J. Neurosci. 19, 10404-10416.

Frank, M. J., Rudy, J. W., and O'Reilly, R. C. (2003). Transitivity, flexibility, conjunctive representations, and the hippocampus: II. A computational analysis. Hippocampus 13, 341-354.
Gabrieli, J. D., Corkin, S., Mickel, S. F., and Growdon, J. H. (1993). Intact acquisition and long-term retention of mirror-tracing skill in Alzheimer's disease and in global amnesia. Behav. Neurosci. 107, 899-910.

Gabrieli, J. D. E., Keane, M. M., Zarella, M. M., and Poldrack, R. A. (1997). Preservation of implicit memory for new associations in global amnesia. Psychol. Sci. 8, 326-329.

Gooding, P. A., Mayes, A. R., van Eijk, R., Meudell, P. R., and MacDonald, F. L. (1999). Do novel associative word stem completion and cued recall share the same memory retrieval process? Memory 7 , 323-343.

Goshen-Gottstein, Y., and Moscovitch, M. (1995). Repetition priming effects for newly formed associations are perceptually based: evidence from shallow encoding and format specificity. J. Exp. Psychol. Learn. Mem. Cogn. 21, 1249-1262.

Goshen-Gottstein, Y., Moscovitch, M., and Melo, B. (2000). Intact implicit memory for newly formed verbal associations in amnesic patients following single study trials. Neuropsychology 14, 570-580.

Graf, P., and Schacter, D. L. (1985). Implicit and explicit memory for new associations in normal and amnesic subjects. J. Exp. Psychol. Learn. Mem. Cogn. 11, 501-518.

Greene, A. J. (2007). Human hippocampal-dependent tasks: is awareness necessary or 18 , sufficient? Hiippocampus 17, 429-433.

Greene, A. J., Gross, W. L., Elsinger, C. L., and Rao, S. M. (2006). An fMRI analysis of the human hippocampus: inference, context, and task awareness. J. Cogn. Neurosci. 18, 1156-1173.

Greene, A. J., Gross, W. L., Elsinger, C. L., and Rao, S. M. (2007). Hippocampal differentiation without recognition: an fMRI analysis of the contextual cueing task. Learn. Mem. 14, 548-553.

Greene, A. J., Spellman, B. A., Dusek, J. A., Eichenbaum, H. B., and Levy, W. B. (2001). Relational learning with and without awareness: transitive inference using nonverbal stimuli in humans. Mem. Cognit. 29, 893-902. Hannula, D. E., Althoff, R. R., Warren, D. E., Riggs, L., Cohen, N. J., and 
Ryan, J. D. (2010). Worth a glance: using eye movements to investigate the cognitive neuroscience of memory. Front. Hum. Neurosci. 4:166. doi: 10.3389/fnhum.2010.00166

Hannula, D. E., Baym, C. L., Warren, D. E., and Cohen, N. J. (2012). The eyes know: eye movements as a veridical index of prior exposure. Psychol. Sci. 23, 278-287.

Hannula, D. E., and Ranganath, C. (2009). The eyes have it: hippocampal activity predicts expressions of memory in eye movements. Neuron 63, 592-599.

Hannula, D. E., Ryan, J. D., Tranel, D., and Cohen, N. J. (2007). Rapid onset relational memory effects are evident in eye movement behavior, but not in hippocampal amnesia. $J$. Cogn. Neurosci. 19, 1690-1705.

Hannula, D. E., Simons, D. J., and Cohen, N. J. (2005). Imaging implicit perception: promise and pitfalls. Nat. Rev. Neurosci. 6, 247-255.

Haskins, A. L., Yonelinas, A. P., Quamme, J. R., and Ranganath, C. (2008). Perirhinal cortex supports encoding and familiarity-based recognition of novel associations. Neuron 59, 554-560.

Hayhoe, M. M., Bensinger, D. G., and Ballard, D. H. (1997). Task constraints in visual working memory. Vision Res. 38, 125-137.

Henderson, J. M., and Hollingworth, A. (2003). Eye movements and visual memory: detecting changes to saccade targets in scenes. Percept. Psychophys. 65, 58-71.

Henke, K. (2010). A model for memory systems based on processing modes rather than consciousness. Nat. Rev. Neurosci. 11, 523-532.

Henke, K., Treyer, V., Nagy, E. T., Kneifel, S., Dursteler, M., Nitsch, R. M., and Buck, A. (2003a). Active hippocampus during nonconscious memories. Conscious. Cogn. 12, 31-48.

Henke, K., Mondadori, C. R. A., Treyer, V., Nitsch, R. M., Buck, A., and Hock, C. (2003b). Nonconscious formation and reactivation of semantic associations by way of the medial temporal lobe. Neuropsychologia 41, 863-876.

Henson, R. N. A. (2003). Neuroimaging studies of priming. Prog. Neurobiol. 70, 53-81.

Holender, D. (1986). Semantic activation without conscious identification in dichotic listening, parafoveal vision, and visual masking: a survey and appraisal. Behav. Brain Sci. 9, $1-66$.

Hollingworth, A., Williams, C. C., and Henderson, J. M. (2001). To see and remember: visually specific information is retained in memory from previously attended objects in natural scenes. Psychon. Bull. Rev. 8, 761-768.

Hollingworth, A., Richard, A. M., and Luck, S. J. (2008). Understanding the function of visual short-term memory: transsaccadic memory, object correspondence, and gaze correction. J. Exp. Psychol. Gen. 137, 163-181.

Hollingworth, A., and Henderson, J. M. (2002). Accurate visual memory for previously attended objects in natural scenes. J. Exp. Psychol. Hum. 28, 113-136.

Jiang, Y., and Wagner, L. C. (2004). What is learned in spatial contextual cuing - configuration or individual locations? Percept. Psychophys. 66, 454-463.

Leo, P. D., and Greene, A. J. (2008). Is awareness necessary for true inference? Mem. Cognit. 36, 1079-1086.

Light, L. L., Kennison, R., Prull, M. W., LaVoie, D., and Zuellig, A. (1996). One-trial associative priming of nonwords in young and older adults. Psychol. Aging 11, 417-430.

Maine de Biran, F. P. G. (1804/1929). The Influence of Habit on the Faculty of Thinking. Baltimore: Williams and Wilkins.

Manns, J. R., and Squire, L. R. (2001). Perceptual learning, awareness, and the hippocampus. Hippocampus 11, 776-782.

Mayes, A. R., and Gooding, P. G. (1989). Enhancement of word completion priming in amnesics by cueing with previously novel associates. Neuropsychologia 27, 1057-1072.

Mayes, A. R., Gooding, P. A., Hunkin, N. M., Nunn, J. A., Gregory, L. J., Brammer, M. J., Bullmore, E. T., Giampietro, V., VanEijk, R., Nicholas, A. K., and Williams, S. C. (1998). Storage of verbal associations is sufficient to activate the left medial temporal lobe. Behav. Neurol. 11, 163-172.

McKone, E., and Slee, J. A. (1997). Explicit contamination in implicit memory for new associations. Mem. Cognit. 25, 352-366.

Milner, B. (1962). "Les troubles de la memoire accompagnant les lesions hippocampiques bilaterales," in Physiologie de l'Hippocampe, Colloques Internationaux, No. 107 (Paris: C.N.R.S.), 257-272.

Milner, B., Corkin, S., and Teuber, H. L. (1968). Further analysis of the hippocampal amnesic syndrome: 14-year follow-up study of H.M. Neuropsychologia 6, 215-234.

Milner, B., Squire, L. R., and Kandel, E. R. (1998). Cognitive neuroscience and the study of memory. Neuron 20, 445-468.

Moscovitch, M. (1992). Memory and working with memory: a component process model based on modules and central systems. J. Cogn. Neurosci. 4, 257-267.

Moscovitch, M. (2008). The hippocampus as a "stupid" domain-specific module: implications for theories of recent and remote memory, and of imagination. Can. J. Exp. Pychol. 62 , 62-79.

Moscovitch, M., and Umilta, C. (1991). "Conscious and nonconscious aspects of memory: a neuropsychological framework of modules and central systems," in Perspectives on Cognitive Neuroscience, eds. $\mathrm{R}$. G. Lister and H. J. Weingartner (Oxford: Oxford University Press), 229-266.

Moscovitch, M., Winocur, G., and McLachlan, D. (1986). Memory as assessed by recognition and reading time in normal and memory impaired people with Alzheimer's disease and other neurological disorders. J. Exp. Psychol. Gen. 115, 331-347.

Moses, S. N., and Ryan, J. D. (2006). A comparison and evaluation of the predictions of relational and conjunctive accounts of hippocampal function. Hippocampus 16, 43-65.

Musen, G., and Squire, L. R. (1993) On the implicit learning of novel association by amnesic patients and normal subjects. Neuropsychology 7 119-135.

Norman, K. A., and O'Reilly, R. C. (2003). Modeling hippocampal and neocortical contributions to recognition memory: a complementary learning systems approach. Psychol. Rev. 110, 611-646.

Paller, K. A., and Mayes, A. R. (1994) New-association priming of word identification in normal and amnesic subjects. Cortex 30, 53-73.

Park, H., Quinlan, J., Thornton, E., and Reder, L. M. (2004). The effect of midazolam on visual search: implications for understanding amnesia Proc. Natl. Acad. Sci. U.S.A. 10 17879-17883.

Pascalis, O., Hunkin, N. M., Bachevalier, J., and Mayes, A. R. (2009). Change in background context disrupts performance on visual paired comparison task following hippocampal damage. Neuropsychologia 47 2107-2113.

Pessoa, L., and Adolphs, R. (2010). Emotion processing and the amygdala: from a 'low road' to 'many roads' of evaluating biological significance. Nat. Rev. Neurosci. 11, 773-783.

Poldrack, R. A., and Cohen, N. J. (1997). Priming of new associations in reading time: what is learned? Psychon. Bull. Rev. 4, 398-402.

Postma, A., Kessels, R. P., and van Asselen, M. (2008). How the brain remembers and forgets where things are: the neurocognition of object-location memory. Neurosci. Biobehav. Rev. 32, 1339-1345.

Preston, A. R., and Gabrieli, J. D. (2008). Dissociation between explicit memory and configural memory in the human medial temporal lobe. Cereb. Cortex 18, 2192-2207.

Quamme, J. R., Yonelinas, A. P., and Norman, K. A. (2007). Effect of unitization on associative recognition in amnesia. Hippocampus 17 192-200.

Reder, L. M., Park, H., and Kieffaber, P. D. (2009). Memory systems do not divide on consciousness: reinterpreting memory in terms of activation and binding. Psychol. Bull. $135,23-49$

Reed, J., and Johnson, P. (1994). Assessing implicit learning with indirect tests: determining what is learned about sequence structure. $J$. Exp. Psychol. Learn. Mem. Cogn. 20, 585-594.

Reingold, E. M. (2004). Unconscious perception: assumptions and interpretive difficulties. Conscious. Cogn $13,117-122$.

Reingold, E. M., and Goshen-Gottstein, Y. (1996). Automatic retrieval of new associations under shallow encoding conditions. Conscious. Cogn. 5, 117-130.

Richardson-Klavehn, A., and Bjork, R. A. (1988). Measures of memory. Annu. Rev. Psychol. 39, 475-543.

Ryan, J. D., Althoff, R. R., Whitlow, S., and Cohen, N. J. (2000). Amnesia is a deficit in relational memory. Psychol. Sci. 11, 454-461.

Ryan, J. D., and Cohen, N. J. (2003). Evaluating the neuropsychological dissociation evidence for multiple memory systems. Cogn. Affect. Behav. Neurosci. 3, 168-185.

Ryan, J. D., and Cohen, N. J. (2004). Processing and short-term retention of relational information in amnesia. Neuropsychologia 42, 497-511.

Ryan, J. D., Hannula, D. E., and Cohen, N. J. (2007). The obligatory effects of memory on eye movements. Memory 15, 508-525.

Savage, G. R., Saling, M. M., Davis, C. W., and Berkovic, S. F. (2002). Direct and indirect measures of 
verbal relational memory following anterior temporal lobectomy. Neuropsychologia 40, 302-316.

Schacter, D. L., Addis, D. R., and Buckner, R. L. (2008). Episodic simulation of future events: concepts, data, and applications. Ann. N.Y. Acad. Sci. 1124, 39-60.

Schacter, D. L. (1987). Implicit memory: history and current status. J. Exp. Psychol. Learn. Mem. Cogn. 13, 501-518.

Schacter, D. L., Church, B., and Bolton, E. (1995). Implicit memory in amnesic patients: impairment of voice-specific priming. Psychol. Sci. 6, 20-25.

Schacter, D. L., Dobbins, I. G., and Schnyer, D. M. (2004). Specificity of priming: a cognition neuroscience approach. Nat. Rev. Neurosci. 5, 852-862.

Schacter, D. L., and Graf, P. (1986). Implicit and explicit memory for new associations in normal and amnesic subjects. J. Exp. Psychol. Learn. Mem. Cogn. 11, 501-518.

Schendan, H., Searl, M. M., Melrose, R. J., and Stern, C. E. (2003a). An fMRI study of the role of the medial temporal lobe in implicit and explicit sequence learning. Neuron 37, 1013-1025.

Schendan, H., Searl, M. M., Melrose, R. J., and Stern, C. E. (2003b). Sequence? what sequence?: the human medial temporal lobe and sequence learning. Mol. Psychiatry 8, 896-897.

Scoville, W. B., and Milner, B. (1957). Loss of recent memory after bilateral hippocampal lesions. J. Neurol. Neurosurg. Psychiatr. 20, 11-21.

Shanks, D. R., Channon, S., Wilkinson, L., and Curran, H. V. (2006). Disruption of sequential priming in organic and pharmacological amnesia: a role for the medial temporal lobes in implicit contextual learning. Neuropsychopharmacology 31, 1768-1776.

Sheldon, S. A., and Moscovitch, M. (2010). Recollective performance advantages for implicit memory tasks. Memory 18, 681-697.

Shimamura, A. P. (2011). Episodic retrieval and the cortical binding of relational activity. $\operatorname{Cog} n$.
Affect. Behav. Neurosci. 11, Turk-Browne, N. B., Scholl, B. J., 277-291.

Shimamura, A. P., and Squire, L. R. (1989). Impaired priming of new associations in amnesia. J. Exp. Psychol. Learn. Mem. Cogn. 15, 721-728.

Simons, D. J., Hannula, D. E., Warren, D. E., and Day, S. W. (2006). "Behavioral, neuroimaging and neuropsychological approaches to implicit perception," in Cambridge Handbook of Consciousness, eds D. Zelazo, M. Moscovitch, and E. Thompson (New York, NY: Cambridge University Press), 207-250.

Smith, C. N., Hopkins, R. O., and Squire, L. R. (2006). Experiencedependent eye movements, awareness, and hippocampusdependent memory. J. Neurosci. 26, 11304-11312.

Smith, C. N., and Squire, L. R. (2005). Declarative memory, awareness, and transitive inference. J. Neurosci. 25 , 10138-10146.

Smyth, A. C., and Shanks, D. R. (2008). Awareness in contextual cuing with extended and concurrent explicit tests. Mem. Cognit. 36, 403-415.

Squire, L. R. (2004). Memory systems of the brain: a brief history and current perspective. Neurobiol. Learn. Mem. 82, 171-177.

Squire, L. R., and Cohen, N. J. (1984). "Human memory and amnesia," in Neurobiology of Learning and Memory, eds G. Lynch, J.L. McGaugh, and N.M. Weinberger (New York, NY: The Guilford Press), 3-64.

Squire, L. R., Stark, C. E. L., and Clark, R. E. (2004). The medial temporal lobe. Annu. Rev. Neurosci. 27, 279-306.

Squire, L. R., Wetzel, C. D., and Slater, P. C. (1978). Anterograde amnesia following ECT: an analysis of the beneficial effects of partial information. Neuropsychologia 16, 339-348.

Turk-Browne, N. B., Scholl, B. J., Chun, M. M., and Johnson, M. K. (2008). Neural evidence of statistical learning: efficient detection of visual regularities without awareness. J. Cogn. Neurosci. 21, 1934-1945.
Johnson, M. K., and Chun, M. M. (2010). Implicit perceptual anticipation triggered by statistical learning. J. Neurosci. 30, 11177-11187.

Tversky, A., and Kahneman, D. (1974) Judgment under uncertainty: heuristic and biases. Science 185, 1124-1131.

Verfaellie, M., Martin, E., Page, K., Parks, E., and Keane, M. M. (2006). Implicit memory for novel conceptual associations in amnesia. Cogn Affect. Behav. Neurosci. 6, 91-101.

Verfaellie, M., Koseff, P., and Alexander, M. P. (2000). Acquisition of novel semantic information in amnesia: effects of lesion location. Neuropsychologia 38, 484-492.

Vilberg, K. L., and Rugg, M. D. (2008) Memory retrieval and the parietal cortex: a review of evidence from a dual-process perspective. Neuropsychologia 46, 1787-1799.

Voss, J. L., Baym, C. L., and Paller, K. A. (2008). Accurate forced-choice recognition without awareness of memory retrieval. Learn. Mem. 15, 454-459.

Voss, J. L., Gonsalves, B. D., Federmeier, K. D., Tranel, D., and Cohen, N. J. (2011). Hippocampal brainnetwork coordination during volitional exploratory behavior enhances learning. Nat. Neurosci. 14, 115-120.

Voss, J. L., and Paller, K. A. (2009) An electrophysiological signature of unconscious recognition memory. Nat. Neurosci. 12, 349-355.

Voss, J. L., and Paller, K. A. (2010). What makes recognition without awareness appear to be elusive? Strategic factors that influence the accuracy of guesses. Learn. Mem. 17, 460-468.

Wagner, A. D., Shannon, B. J., Kahn, I. and Buckner, R. L. (2005). Parietal lobe contributions to episodic memory retrieval. Trends Cogn. Sci. 9, 445-453.

Warrington, E. K., and Weiskrantz, L. (1968). New method of testing longterm retention with special reference to amnesic patients. Nature 217, 972-974.

Westerberg, C. E., Miller, B. B., Reber, P. J., Cohen, N. J., and Paller, K
A. (2011). Neural correlates of contextual cueing are modulated by explicit learning. Neuropsychologia 49, 3439-3447.

Wheeler, M. E., and Buckner, R. L. (2003). Functional dissociation among components of remembering: control, perceived oldness, and content. J. Neurosci. 23, 3869-3880.

Wolfe, J. M. (1999). "Inattentional amnesia," in Fleeting Memories: Cognition of Brief Visual Stimuli, ed V. Coltheart (Cambridge, MA: MIT Press), 71-94.

Yang, J., Weng, X., Guan, L., Kuang, P., Zhang, M., Sun, W., Yu, S., and Patterson, K. (2003). Involvement of the medial temporal lobe in priming for new associations. Neuropsychologia 41, 818-829.

Yang, J., Meckingler, A., Xu, M., Zhao, Y., and Weng, X. (2008). Decreased parahippocampal activity in associative priming: evidence from an event-related fMRI study. Learn. Mem. 15, 703-710.

Yonelinas, A. P., and Jacoby, L. L. (1994). Dissociations of processes in recognition memory: effects of interference and of response speed. Can. J. Exp. Psychol. 48, 516-535.

Conflict of Interest Statement: The authors declare that the research was conducted in the absence of any commercial or financial relationships that could be construed as a potential conflict of interest.

Received: 18 October 2011; accepted: 21 March 2012; published online: 12 April 2012.

Citation: Hannula DE and Greene AJ (2012) The hippocampus reevaluated in unconscious learning and memory: at a tipping point?. Front. Hum. Neurosci. 6:80. doi: 10.3389/fnhum.2012.00080 Copyright (C) 2012 Hannula and Greene. This is an open-access article distributed under the terms of the Creative Commons Attribution Non Commercial License, which permits non-commercial use, distribution, and reproduction in other forums, provided the original authors and source are credited. 